\title{
REVIEW ARTICLE OPEN \\ Painful intervertebral disc degeneration and inflammation: from laboratory evidence to clinical interventions
}

\author{
Feng-Juan Lyu ${ }^{1}$, Haowen Cui ${ }^{2}$, Hehai Pan ${ }^{3,4}$, Kenneth MC Cheung ${ }^{5}$, Xu Cao ${ }^{6}$, James C. latridis $\mathbb{D}^{7}$ and Zhaomin Zheng ${ }^{2,8}$
}

Low back pain (LBP), as a leading cause of disability, is a common musculoskeletal disorder that results in major social and economic burdens. Recent research has identified inflammation and related signaling pathways as important factors in the onset and progression of disc degeneration, a significant contributor to LBP. Inflammatory mediators also play an indispensable role in discogenic LBP. The suppression of LBP is a primary goal of clinical practice but has not received enough attention in disc research studies. Here, an overview of the advances in inflammation-related pain in disc degeneration is provided, with a discussion on the role of inflammation in IVD degeneration and pain induction. Puncture models, mechanical models, and spontaneous models as the main animal models to study painful disc degeneration are discussed, and the underlying signaling pathways are summarized. Furthermore, potential drug candidates, either under laboratory investigation or undergoing clinical trials, to suppress discogenic LBP by eliminating inflammation are explored. We hope to attract more research interest to address inflammation and pain in IDD and contribute to promoting more translational research.

\section{INTRODUCTION}

Low back pain (LBP) is a common clinical symptom occurring predominantly in middle to old age. ${ }^{1}$ In 2015 , the prevalence of LBP in adults worldwide was 7.3\%. From 1990 to 2015, the number of people with disabilities due to LBP increased by $54 \% .^{2}$ In total, $\sim 40 \%$ of the population suffers from LBP during their lifetime. ${ }^{3}$ This condition is now the number one cause of the world's disability burden. ${ }^{4}$ Recurrent LBP impairs the patient's physical and mental health and places a heavy burden on health care and social support systems. ${ }^{5}$

Intervertebral discs (IVDs) are complex fibrocartilaginous tissues that connect adjacent vertebral bodies to enable spinal motion. IVD degeneration (IDD) increases with age, with more than $80 \%$ of IVDs exhibiting degeneration-related changes in people over 50 years old. ${ }^{6}$ IDD is a widely recognized cause of back pain. ${ }^{7,8}$ During IDD, IVD cells exhibit increased proinflammatory cytokines. ${ }^{7,8}$ Degeneration also results in degradation of the extracellular matrix and loss of hydrophilic matrix molecules, which can lead to structural and biomechanical changes ${ }^{9}$ and is a leading cause of increased inflammation, nerve ingrowth ${ }^{10,11}$ and release of pain factors. ${ }^{12}$

IDD is a complex process. Proinflammatory conditions may be a critical factor in IDD., ${ }^{7,8}$ Recent research has identified inflammatory mediators and signaling pathways as important factors in the onset and progression of disc degeneration. ${ }^{13}$ Inflammation mediated by immune cells was enhanced in degenerated IVDs, and degradation products of these cells, such as IL-4, IL-6, IL-12,
IFN- $\gamma$, and MMPs, led to a reduction in NP cell number and deterioration of the IVD microenvironment. ${ }^{14}$ Long-term inflammation recruits inflammatory cells, which further exacerbate this situation. ${ }^{15}$ Furthermore, inflammatory mediators such as TNF-a and IL-1 $\beta$ induce the expression of pain-related factors such as nitric oxide (NO), cyclooxygenase 2 (COX-2), and nerve growth factors (NGF), which promote nerve ingrowth. ${ }^{12}$ All of these factors together contribute to the occurrence of LBP.

Treating discogenic LBP requires a good understanding of IDD and the underlying inflammation. Similarly, basic and translational science studies are most potent when they consider treatments for IDD, including their effects on pain relief. Historically, laboratory research has often focused on the biological repair of injured or degenerated IVDs with less attention given to pain suppression. However, clinical research has often emphasized the urgent need of patients for pain relief without sufficient attention to how these approaches can slow IDD or promote healing. This gap between clinical and basic research is receiving increased attention and narrowing, while researchers take a more holistic approach to science and patient care in their study designs.

In this review, we tried to provide an overview of discogenic LBP studies with a focus on advances in inflammation-related pain in IDD. We review the role of inflammation in IDD and pain induction, as well as the currently available animal models for the study of painful IDD and the underlying signaling pathways contributing to inflammation and discogenic pain production.

\footnotetext{
${ }^{1}$ School of Medicine, South China University of Technology, Guangzhou, China; ${ }^{2}$ Department of Spine Surgery, The First Affiliated Hospital, Sun Yat-Sen University, Guangzhou, China; ${ }^{3}$ Guangdong Provincial Key Laboratory of Malignant Tumor Epigenetics and Gene Regulation, Sun Yat-sen Memorial Hospital, Sun Yat-sen University, Guangzhou, China; ${ }^{4}$ Breast Tumor Center, Sun Yat-sen Memorial Hospital, Sun Yat-sen University, Guangzhou, China; ${ }^{5}$ Department of Orthopedics \& Traumatology, The University of Hong Kong, Hong Kong, SAR, China; ${ }^{6}$ Department of Orthopedic Surgery, Johns Hopkins University, Baltimore, MD, USA; ${ }^{7}$ Leni and Peter W. May Department of Orthopedics, Icahn School of Medicine at Mount Sinai, New York, NY, USA and ${ }^{8}$ Pain Research Center, Sun Yat-sen University, Guangzhou, China

Correspondence: Zhaomin Zheng (zhengzm1@163.com)

These authors contributed equally: Feng-Juan Lyu, Haowen Cui, Hehai Pan
}

Received: 2 February 2020 Revised: 1 October 2020 Accepted: 9 October 2020

Published online: 29 January 2021 
In addition, we explored laboratory and clinical pain elimination candidates and trials under development. Overall, we hope this review contributes to filling the gap between laboratories and clinics by clarifying the current understanding of how pain is produced in disc degeneration and inflammation, what kind of animal models we can use to study discogenic pain, and what strategies we are currently developing.

\section{DISC DEGENERATION IS AN IMPORTANT CAUSE OF LBP}

Structure of healthy IVDs

Healthy IVDs are a three-part complex consisting of a gelatinous proteoglycan-rich nucleus pulposus (NP) in the center, the interwoven collagenous layers of annulus fibrosus (AF) on its periphery, and cartilaginous and vertebral endplates (EP) on the superior and inferior surfaces. The NP is subjected to high pressure, which is resisted by the substantial hoop stress of the AF to prevent the outward expansion of the NP. AF resists large tensile and compressive strains when a torsional strength is applied to the disc. Under normal conditions, NP and AF work together to provide the mechanical properties of the IVD to maintain a high-stress load on the vertebral body.

\section{Degenerative IVD}

The etiology of IDD is complicated. Most degeneration begins in adults and progresses with age. ${ }^{16}$ The large vacuolated notochordal-like cells in the NP start to disappear at an earlier stage of life at $\sim 10$ years of age, which some consider to be the initiation of the degenerative process. ${ }^{17}$ Although endogenous progenitor cells have been found in the disc, ${ }^{18}$ indicating the potential for self-repair, there is a lack of evidence of spontaneous regeneration in the human IVD. Consequently, the synthesis of proteoglycans is reduced, accompanied by the conversion of collagen synthesis, in which type II collagen is reduced and type I and type III collagen are increased (Fig. 1). ${ }^{19}$ In addition, the synthesis/activity of matrix metalloproteinase (MMP) is increased. ${ }^{20}$ Apoptotic NP cells are also significantly increased. ${ }^{21}$ Calcification of the cartilage endplates results in a reduced supply of nutrients to the intervertebral disc, ${ }^{22}$ further exacerbating the process. EP sclerosis is also reported with EP calcification and ossification caused by aberrant mechanical loading. ${ }^{23}$ Degradation of the extracellular matrix (ECM) and loss of proteoglycans result in a decreased loading capacity and height of the IVD. ${ }^{7}$ The high osmotic pressure and acidic environment in the IVD further exacerbate the stress state. ${ }^{21}$
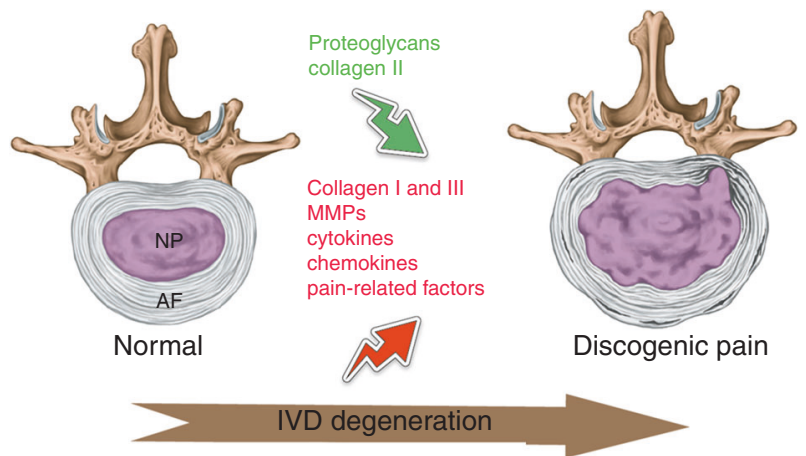

Fig. 1 Illustration of degenerative changes in painful intervertebral discs. During IVD degeneration, proteoglycans and collagen II are decreased, while collagen I and III are increased in the extracellular matrix. Emerging cytokines, chemokines, and pain-related factors synergistically contribute to discogenic pain development. IVD intervertebral disc, NP nucleus pulposus, AF annulus fibrosus
Degenerative IVD and discogenic pain

Discogenic pain refers to pain induced by degenerative changes in the IVD, resulting in the early stages of disc degeneration. ${ }^{24}$ Numerous studies have confirmed that LBP and IDD are closely connected. Arnbak et al. performed an analysis of 1037 patients with persistent LBP, confirming that the LBP incidence increased with the degree of degeneration. ${ }^{25}$ Middendorp et al. found that the Oswestry Disability Index (ODI) for patients with LBP also correlates with disc degeneration grade. ${ }^{26}$ Similarly, an increased IVD Pfirrmann grade was accompanied by an increase in ODI in patients. ${ }^{26}$ In one study, $87 \%$ of patients with persistent LBP had disc degeneration. ${ }^{27}$ Pain-related molecules, including tumor necrosis factor (TNF) alpha, interleukin (IL)-1 beta, IL-4, IL-6, IL-8, $\mathrm{IL}-12$, prostaglandin E2 (PGE2), interferon-gamma, and nitric oxide (NO), were found to be upregulated in herniated human IVDs., 28

In healthy spines, only the outer AF is innervated. ${ }^{29}$ Animal models and human clinical specimens have shown sensory innervation in the lumbar disc and sensory nerve ingrowth to the inner layer of the disc, ${ }^{30-32}$ which is an important cause of pain. ${ }^{29,33}$ In degenerated and herniated discs, nerves were found to be localized in distorted tissues. ${ }^{34}$ In a spontaneously degenerating mouse model, age-dependent increases in sensory innervation were found in the IVDs. ${ }^{35}$ Increasing innervation was also found in vertebral endplates from discogenic LBP patients with modic changes. $^{36}$ The identified inducers of nerve ingrowth include TNFa, IL-1, ${ }^{37-39}$ and NGF. ${ }^{33}$ The discogenic pain signal passes through the IVD and adjacent structures and is transmitted through peripheral afferent nerve fibers. ${ }^{29}$ The cells are located in the DRG and projected by projection neurons in the spinal dorsal horn to the brain region. Analysis of the role of the peripheral nervous system during painful IDD has become an essential area of research. ${ }^{29,40-42}$ Nerve fibers interact with inflammatory mediators in the NP and cause discogenic LBP. ${ }^{30}$ Compared with herniated IVDs, painful discs contain more inflammatory mediators. ${ }^{43}$

However, not all patients with disc degeneration are symptomatic $^{44}$ with LBP. ${ }^{45}$ Studies have shown that the proportion of severely degraded but painless IVDs increases with age. ${ }^{26,46}$ The lack of persistent inflammation might be crucial to determine whether a degenerated disc becomes symptomatic. ${ }^{47}$ Taken together, these reports strongly suggest a correlation between sensory nerve ingrowth, inflammatory mediators, and discogenic LBP.

\section{ANIMAL MODELS OF PAINFUL IVD DEGENERATION}

Animal experiments are indispensable for studying painful disc degeneration and inflammation. The establishment of an animal model of experimental IDD can provide experimental methods for studying painful IDD. Ideally, among all species, primates are ideal for studying LBP, as they are the species closest to humans. Other large animal models include pigs, ${ }^{48}$ sheep, ${ }^{49}$ goats, ${ }^{50}$ and dogs. ${ }^{51}$ Rodent models are the most widely used animal model for studying LBP. 42

Here, we discuss available animal models of IDD with documented pain symptoms. These animal models can be classified into three categories (Fig. 2): (1) needle puncture models, (2) mechanical models that apply abnormal mechanical stress to the IVD, and (3) spontaneous IDD models.

\section{IVD puncture models}

The disc puncture models involve performing puncture through the posterior or anterior direction. Olmarker punctured lumbar IVDs from the posterior direction with a $0.4 \mathrm{~mm}$ diameter needle in rats. $^{52}$ Posterior puncture could induce spontaneous pain behavior, such as increased "grooming" and "wet-dog shakes". 52 In this model, the left facet joint was removed, and the structure of the posterior column was destroyed to some extent. The resulting disc degeneration and pain may contribute to spinal instability. To explain the mechanism of this behavioral change, Nilsson et al. 


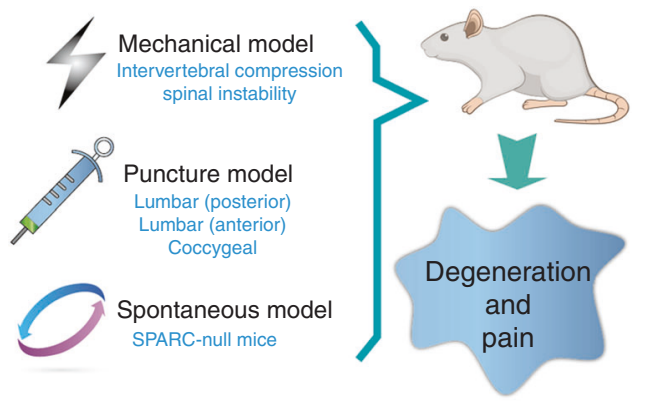

Fig. 2 Animal models of painful IVD degeneration. These models include a mechanical model, a needle puncture model through a posterior or anterior approach, and a spontaneous IVD degeneration and LBP model represented by SPARC-null mice. IVD intervertebral disc, LBP low back pain, SPARC secreted protein acidic and rich in cysteine

compared rats that received superficial disc injury without NP leakage and healthy NP. The study showed that the NP leakage effects were more pronounced than the effects induced by disc injury. ${ }^{53}$

Instead of posterior puncture, Kim et al. used anterior surgery to remove the rat NP through the ventral aspect of abdomens. This process led to inflammatory cell infiltration, proteoglycan loss, and intervertebral height reduction. Nine weeks after the surgery, pain behavior represented by pressure hyperalgesia developed over the lower back. $^{54}$ Lee et al. studied IVD degenerative changes with pain development after a $10 \mathrm{~mL}$ CFA (complete Freund's adjuvant) injection into adult rat lumbar IVDs through an anterior approach. A significant increase in pain, assessed by the hind paw withdrawal response, occurred at 7 weeks postoperatively, accompanied by increased calcitonin gene-related peptide (CGRP) and inducible nitric oxide synthase (iNOS) expression in the DRG. ${ }^{55}$ Lai et al. further modified the anterior model by intradiscal injection of saline into rat lumbar IVDs, which resulted in increased pain, as evaluated by increased grooming duration, decreased mechanical withdrawal thresholds, and decreased thermal withdrawal latency. ${ }^{56}$ Later, both Lai et al. ${ }^{57}$ and Evashwick-Rogler et al. ${ }^{39}$ punctured lumbar IVDs anteriorly, and found that TNF-a injection had a greater and more consistent increase in pain, while an anti-TNF-a antibody alleviated pain to sham levels. The pain threshold was also found to be linearly associated with IDD and intradiscal TNF- $a$ expression ${ }^{39}$ and substance $P$ expression in the DRG. ${ }^{57}$ These results indicated that anterior disc injection of TNF-a is a useful painful disc degeneration model. Millecamps also induced LBP in mice by lumbar anterior disc puncture ${ }^{58}$ and observed the development of pain behavioral signs such as tail suspension and grip force, radiating hypersensitivity, and motor impairment, accompanied by increased dorsal innervation and reduced disc height. ${ }^{58}$

In addition to that of lumbar discs, puncture at the coccygeal disc level can induce pain behavior. Isma described a novel rat coccygeal model of pain induced by a puncture at levels $\mathrm{C5}-\mathrm{C} 6$ and/or C4-C5. ${ }^{59}$ Both thermal hyperalgesia and mechanical allodynia, which were detected by applying stimuli to the tail's ventral base, were found to evoke puncture-induced disc formation in the rat tail. Thermal hypoalgesia-induced changes were also observed in the ventral middle part of the tail through tail-flick testing. ${ }^{59}$

The onset of inflammation might play an important role in pain development in these puncture models. Lee et al. found that pathological innervation lasted up to 12 months in the anterior puncture mouse model, while macrophage infiltration started from day 4 post surgery both dorsally and ventrally. ${ }^{60}$ Most importantly, the large amount of inflammatory mediators behind the disc chemically and biologically stimulate spinal nerve roots. ${ }^{7}$
In another study, no pain behavior changes were detected with anterior disc puncture, whereas posterior disc puncture resulted in mechanical allodynia lasting from 1 day to 21 days postoperatively. ${ }^{61}$ Interestingly, in this study, increased inflammatory cytokines were detected in the DRG after posterior but not anterior puncture, ${ }^{61}$ which indicates that inflammatory factors are indispensable for producing pain.

Mechanical animal model

Mechanical animal models induce disc degeneration by altering the normal biomechanical state. These models include the hindlimb unloading model, ${ }^{62}$ bipedal animal model, ${ }^{63}$ caudal spine mechanical animal model, ${ }^{64-66}$ tail bend model, ${ }^{67}$ and spine instability model. ${ }^{68}$ Among these models, only the caudal spine mechanical and spine instability models have been demonstrated to simulate LBP.

For the caudal spine mechanical models, pain-associated molecule expression was investigated instead of pain behavior changes. Chubinskaya et al. used a vertebral compression rat model to study the relationship between stress and pain. ${ }^{69}$ Two $0.8 \mathrm{~mm}$-diameter Kirschner's wires were inserted percutaneously through the third and fifth coccygeal vertebrae. Each wire was fixed separately to a specially designed aluminum ring consisting of two $30 \mathrm{~mm}$ diameter external rings. Two rings were linked with four rods to immobilize and chronically compress Kirschner's wires until the tail offered maximum angular deformity. The compressed IVD showed signs of degeneration and inflammation, including the appearance of MMP-13, TNF-alpha, and IL-1 beta, as well as the expression of pain-related molecular markers, such as substance P. ${ }^{69}$ Using coccygeal IVD compression devices, Moyagi et al. demonstrated that disc compression in rats produces a longlasting increase in inflammatory mediators in IVDs and neuropeptides, such as CGRP and growth-associated phosphoprotein 43, in DRGs. ${ }^{70}$ Moreover, disc compression induced persistent expression of activating transcription factor $3 a$, a nerve injury marker, and regeneration of the afferent fibers innervating IVDs. ${ }^{70}$ Suzuki et al. also found sustained upregulation of CGRP in DRG neurons in osteoporotic vertebrae after compression. ${ }^{71}$

The spinal instability model was first established by disrupting the spine structure. A mouse spondylosis model was prepared via surgical resection of the posterior spinal element. Ariga et al. observed a large amount of cell apoptosis and destruction of EP in the IVD of the spondylosis model compared with naturally aged IVD. ${ }^{68}$ Fukui et al. established a rat spinal instability model by completely resecting the bilateral L4-L5 facet joints. IDD, LBP, and neuropathic pain accompanying gait abnormalities were observed in this model after 7 weeks. ${ }^{72,73}$ Bian and Zheng et al. ${ }^{74,75}$ resected the lumbar 3rd to 5th (L3-L5) spinous processes along with the supraspinous and interspinous ligaments to promote instability of the mouse lumbar spine, which produced stable degeneration without significant kyphosis. ${ }^{74,76}$ In this model, pain was found to be caused by netrin-1 $1^{+}$osteoclasts that initiate porosity of endplates and sensory innervation. ${ }^{77}$

\section{Spontaneous disc degeneration model}

Secreted protein acidic and rich in cysteine (SPARC) is a matricellular protein involved in collagen deposition, cell-ECM interactions, and ECM remodeling. ${ }^{78}$ IVD cells of elderly subjects with disc degeneration had reduced SPARC expression. ${ }^{79}$ SPARCnull mice showed defective connective tissue ${ }^{80}$ and accelerated disc degeneration. ${ }^{80,81}$ More importantly, SPARC-null mice displayed behavioral signs indicating chronic low back and radicular pain. ${ }^{82}$ The development of behavioral signs of axial and radiating $L B P$ and reduced physical function increased with aging in SPARC-null mice. ${ }^{83}$ Interestingly, SPARC-null mice displayed cold hypersensitivity and avoidance of stretching along the spine's axis but were not mechanically or thermally hypersensitive. Moreover, the sensitivity was site-specific; the hind paw and 
Table 1. Comparison of animal models for painful disc degeneration

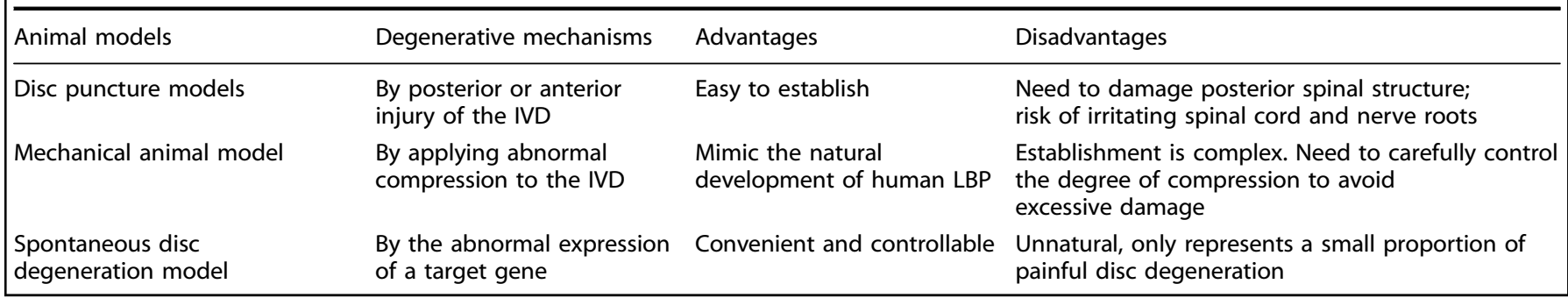

back, but not the tail, were cold sensitive. Furthermore, icilinevoked behavior increased subsequent applications to the hind paw but not the lip. ${ }^{84}$

Summary of the above animal models

All the above mentioned animal models are similar in that they can cause disc degeneration with measurable pain development. Due to the different methods adopted in these models to compromise the IVD, they have unique advantages and disadvantages, as summarized in Table 1. IVD puncture models are established through posterior or anterior injury of the disc, and they have the advantage of ease of establishment despite some drawbacks. Posterior disc puncture will inevitably damage the posterior spinal structure. Resection of the spinous processes and lamina can cause kyphosis in animals. In addition, the physical-mechanical puncture itself has a risk of irritating the spinal cord and nerve roots, which will bias the study. The caudal spine mechanical models mimic the natural development of human LBP by applying abnormal compression, therefore representing a more natural procedure of pain development. However, the establishment of these models is complex and requires skillful techniques. It will be difficult to universally adopt this model. The spine instability models take advantage of the abnormal stress generated by the unstable spine on the IVD; however, the effect of this stress may cause excessive destruction of the posterior column and lead to severe kyphosis. ${ }^{23}$ Therefore, the scope of spine injury must be carefully designed. As a spontaneous disc degeneration model, SPARC-null mice provide a convenient and controllable model to study spontaneous disc degeneration and pain. ${ }^{41,85}$ However, these mice also have some shortcomings as a genetically modified model. The lack of SPARC may affect IVD in multiple ways in addition to what we already know. Conversely, SPARC deficiency may not be fully responsible for IDD, and pain occurs under natural conditions.

\section{THE ASSOCIATION OF INFLAMMATION WITH PAINFUL IVD DEGENERATION}

Inflammatory molecules are increased in and further promote IVD degeneration

Increased levels of inflammatory molecules have been found in degenerated IVDs. TNF-a expression was found to be elevated in the IVD and peripheral serum in patients with degenerated IVDs. ${ }^{86}$ Serological analysis of 392 populations demonstrated that IL-6 was increased in patient serum ${ }^{87}$ with IDD as well as in degenerated IVDs ${ }^{88}$ compared to that of healthy controls. Degenerated and herniated IVDs contained increased IL-17 expression and Th17 lymphocyte infiltration. ${ }^{28}$ Gruber et al. also showed elevated IL-17 expression in degenerated human discs and increased production of IL-17 by disc cells under IL-1 $\beta$ and TNF-a stimulation. ${ }^{89}$

Furthermore, inflammatory molecules have been found to initiate or accelerate IDD. The presence of proinflammatory cytokines promotes the degenerative process, thereby exacerbating degenerative symptoms in IVDs. ${ }^{8,90}$ Denaturation is thought to be partially mediated by infiltrating inflammatory cells and further aggravates disc degeneration. ${ }^{91,92}$ Proinflammatory mediators, including TNF- $\alpha$, IL-1a/ $\beta$, IL-2, IL-4, IL-6, IL-8, IL-10, IL-17, IFN- $\gamma$, chemokines, and prostaglandin (PGE) $2,{ }^{7,8,29}$ may also influence the autophagy, senescence, and apoptosis of disc cells. ${ }^{93-96}$ As the key inflammatory mediators of disc degeneration, TNF- $\alpha$ and IL-1 $\beta$ can induce disc degeneration by decreasing anabolic ECM proteins, such as aggrecan and collagen II, and promoting catabolic enzymes, such as a disintegrin and metalloproteinase with thrombospondin motifs (ADAMTS)- 4 and -5 and matrix metalloproteinases (MMPs)-1, $-2,-3,-4,-13$, and $-14 .{ }^{97-105}$ TNF-a suppresses the production of ECM, including collagen, aggrecan, and fibromodulin, but increases the expression of MMP-3, -9 , and -13 and NGF. ${ }^{106}$ TNF- $\alpha$ and $\mathrm{IL}-1 \beta$ also regulate chemokine (C-C motif) ligand 3 (CCL3) expression in NP cells and promote macrophage infiltration through the CCL3-CCR1 axis in degenerated herniated discs. ${ }^{92}$ TNF-a overexpression in mice resulted in early onset spontaneous IVD herniation without affecting collagen and aggrecan expression in the NP and AF. ${ }^{107}$ Global IL-1a/ $\beta$ knockout in mice resulted in a more degenerative phenotype in the AF and collagen type and maturity changes, accompanied by alterations in systemic cytokine levels and vertebral bone morphology. ${ }^{108}$

In addition, IFN- $\gamma$ and IL-17 synergistically promote the release of inflammatory mediators in disc cells. ${ }^{109} \mathrm{IL}-6$ and IL- 6 soluble receptors synergistically potentiate the catabolic effects of IL-1 $\beta$ and TNF- $\alpha$ on human NP cells, along with COX-2 and PGE-2 levels. ${ }^{110}$

In summary, inflammatory cytokines are elevated in degenerated IVDs, and when used as stimuli, they could cause or exacerbate disc degeneration. Therefore, inflammation plays an important role in the degeneration of IVDs.

Inflammatory molecules are increased in and can cause discogenic pain

Innervation is thought to be an important process in the production of discogenic pain. IVD tissue is generally thought to contain no neural structure, but studies have found that the outer annular layer of the healthy IVD has nerve fibers that rarely extend into the inner AF and NP. ${ }^{111,112}$ The normal IVD is primarily innervated by small DRG neurons consisting of NGF-dependent and glial cell line-derived neurotrophic factor (GDNF)-dependent neurons, which express highaffinity NGF and the brain-derived neurotrophic factor (BDNF) receptors TrkA, TrkB, and GDNF. ${ }^{30}$ Patients with chronic LBP have abundant peripheral nerve fibers in the NP and inner AF. ${ }^{29,30,32}$ During degeneration of the IVD, the nerve fibers gradually extend to the inner layer of the AF and even the NP, accompanied by the expression of pain transmitter substance $\mathrm{P}^{32}{ }^{\prime}$ which is highly relevant to the genesis of discogenic LBP. ${ }^{29,30,32}$

It has been proposed that the expression of inflammatory cytokines is increased in painful IVDs. ${ }^{7,113}$ The expression of IL-6, IL-8, and PGE2 is increased in IVD samples from patients with LBP. ${ }^{114} \mathrm{IL}-1 \beta$ and IL-6 levels are enhanced in painful herniated discs. ${ }^{115}$ Ingrowth of vascularized granulation tissue along tears was reported, extending from the outer AF to the NP in patients with discogenic LBP, accompanied by abundant macrophage and mast cell infiltration. ${ }^{116}$ Posterior rupture of AF stimulated TNF-a 


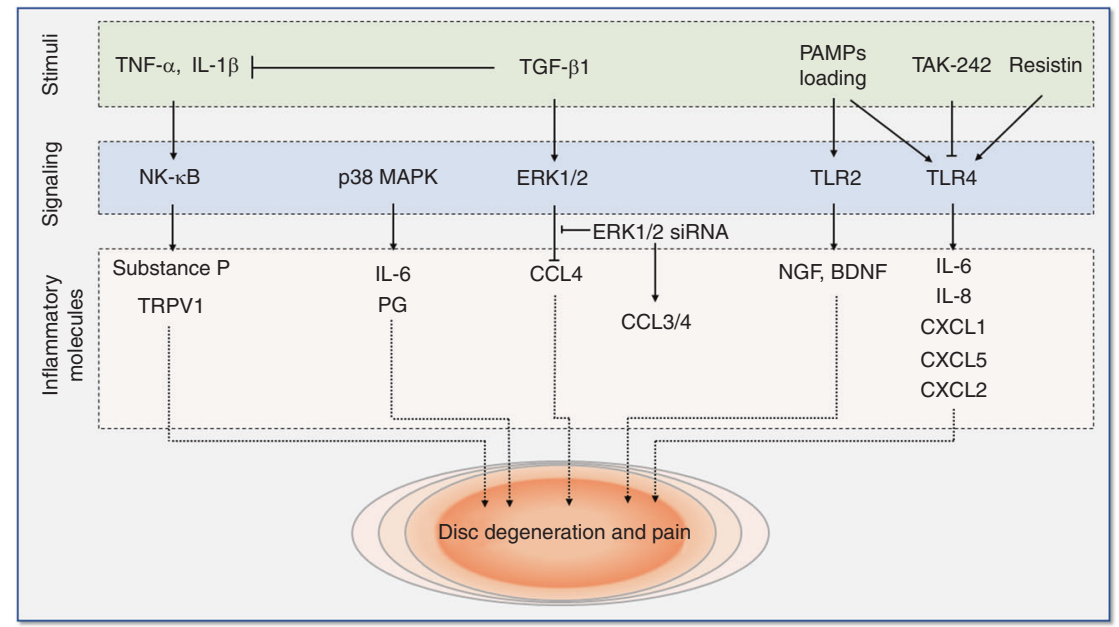

Fig. 3 Signaling pathways involved in intervertebral disc degeneration and pain. These pathways include NF- $\mathrm{B} B$ signaling, MAPK signaling, and TLR signaling. NF- $\kappa B$ nuclear factor kappa-B, MAPK mitogen-activated protein kinase, TLR Toll-like receptor. IL interleukin, TRPV1 transient receptor potential cation channel subfamily $\mathrm{V}$ member 1 , PG prostaglandins, TGF- $\beta 1$ transforming growth factor $\beta 1$, ERK extracellular signalregulated kinases, $\mathrm{CCL}$ chemokine (C-C motif) ligand, PAMP pathogen-associated molecular patterns, NGF nerve growth factor, BDNF brainderived neurotrophic factor, $\mathrm{CXCL}$ chemokine (C-X-C motif) ligand

and IL-1 $\beta$ expression, thus inducing the DRG inflammatory response and mechanical hyperalgesia in a rat model. ${ }^{61}$ Elevated expression of MMP-10, NGF and substance $P$ was found in painful degenerated discs. ${ }^{117}$ These studies indicate that painful discs contain increased levels of proinflammatory mediators.

However, inflammatory factors can cause discogenic pain. Studies have shown that the neurotrophic factors NGF and BDNF contribute to both innervation of degenerating discs and neuronal sensitization ${ }^{10,118,119}$ in mature peripheral afferent fibers and result in the development of chronic pain. ${ }^{120}$ A direct relationship between nociceptive nerve ingrowth and NGF production by blood microvessels was found in painful IVDs. ${ }^{121}$ While degenerative IVDs can secrete many inflammatory and pain mediators, including TNF-a, IL$1 \beta$, IL- 6, IL- 8 , substance $P$, and prostaglandin E2, these factors not only reduce proteoglycan and collagen synthesis but also stimulate nerve fiber ingrowth and induce pain. ${ }^{7}$ Safieh-Garabedian et al. showed that $\mathrm{IL}-1 \beta$ promoted NGF expression during inflammation. ${ }^{122}$ Abe et al. demonstrated that IL-1 $\beta$ and TNF-a stimulated the production of NGF by human IVD cells. ${ }^{123}$ Lai et al. reported that intradiscal TNF-a injection led to more painful behavior and stimulated substance $P$ expression in DRGs compared to saline control. ${ }^{57}$ Purmessur et al. also reported that IL-1 $\beta$ significantly increased the expression of NGF and BDNF, while TNF-a upregulated substance P in human NP cells. ${ }^{124}$ Lee et al. found that IL-1 $\beta$ generated during IDD further stimulated VEGF, NGF, and BDNF production and induced angiogenesis and innervation in degenerative IVDs. ${ }^{125}$ Gruber et al. showed that IL-1 $\beta$ significantly elevated BDNF, neurotrophin 3 , neuropilin 2 , and NGF expression in annulus cells. ${ }^{126}$ Clinically, COX-2 inhibitors, which in turn inhibit PGE2 synthesis, could significantly alleviate LBP. ${ }^{127}$

All these studies suggest that inflammatory cytokines play a major role in the production of NGF, BDNF, and neurotrophins, which results in nerve ingrowth into the disc and thus generates discogenic pain.

\section{SIGNALING PATHWAYS INVOLVED IN PAINFUL IVD DEGENERATION}

Various pathways, such as the nuclear factor kappa-B (NF-kB) and mitogen-activated protein kinase (MAPK) pathways, have been found to play essential roles in the production of inflammatory factors and catabolism of ECM in the IVD, ${ }^{128}$ and increasing evidence supports the importance of these signaling pathways and Toll-like receptor (TLR) signaling in painful disc diseases, as summarized in Fig. 3. ${ }^{41,129-132}$

\section{NF-KB signaling}

NF-KB is a canonical downstream pathway of inflammatory cytokines, such as TNF- $\alpha$ and IL-1 $\beta .^{133}$ NF-KB activity is physically inhibited when an inhibitor of kappa $B$ (IKB) binds to p65. Once stimulated, p65 is rapidly released from the NF-kB heterodimer and $I_{K B}$ and translocates to the nucleus, where it activates the transcription of target genes. Numerous studies have shown that the NF-KB signaling pathway plays a major role in inflammatory cytokine production and secretion, ${ }^{128}$ which is closely associated with disc degeneration and the genesis of discogenic pain.

Recently, it was reported that Propionibacterium acnes induces substance $P$ and CGRP expression in the IVD and obvious LBP symptoms by stimulating NP cells to secrete the pro-algesic factor IL-8/CINC-1 through the TLR2-NF-KB p65 pathway, which may provide a promising alternative therapeutic strategy for LBP patients in the clinic. ${ }^{129}$ Moreover, Ahmed et al. found that NF-KB activation correlates with the expression of substance $P$ and transient receptor potential cation channel subfamily $\mathrm{V}$ member 1 (TRPV1) in IVD tissues and may be associated with the generation or maintenance of peripheral pain by regulating pain-related neuropeptides in patients with degenerative disc diseases. ${ }^{130}$ Walter et al. similarly identified a relationship between TRPV channels and catabolism and found that TNF-a sensitizes IVD cells to induce a proinflammatory and catabolic phenotype under load via TRPV4 signaling. ${ }^{134}$ These new studies indicated that the NF-KB signaling pathway is not only implicated in inflammatory cytokine secretion but also plays a vital role in discogenic pain production.

\section{MAPK signaling}

MAPKs are a family of highly conserved pathways, including three major subfamilies, the extracellular signal-regulated kinases (ERK), c-Jun NH2-terminal kinase (JNK), and p38 isoforms, ${ }^{135}$ allowing the cells to respond to multiple extracellular stimuli, such as hormones, growth factors, inflammatory cytokines, and other stresses. ${ }^{136}$ MAPKs are master regulators of inflammatory responses. A study from Kim et al. showed that p38 MAPK is involved in IL-6 and prostaglandin (PG) secretion from AF cells when cocultured with macrophage-like cells, suggesting that blockade of the p38 MAPK pathway may represent a therapeutic approach to treat discogenic pain. ${ }^{137}$ Zhang et al. demonstrated that TGF- $\beta 1$ significantly decreases CCL4 expression by activating ERK1/2 MAPK signaling in NP cells and prevents disc degeneration. ${ }^{131}$ Interestingly, these researchers also found that TGF- $\beta 1$ alleviates inflammatory responses in the DRG and 


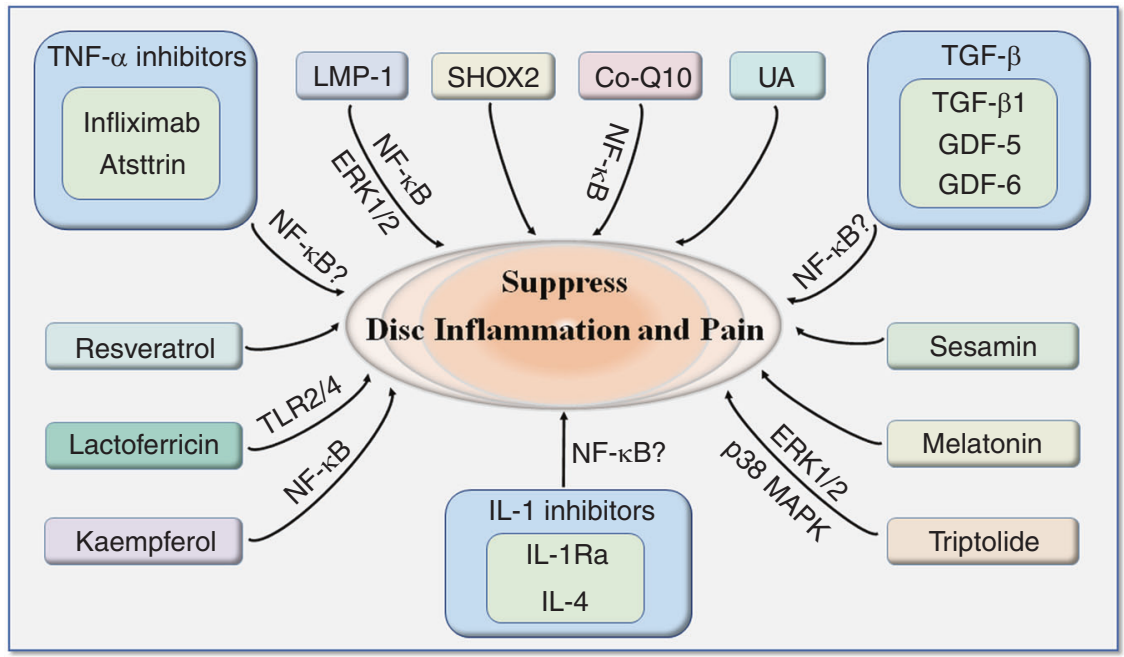

Fig. 4 Molecules under laboratory investigation to target inflammation and discogenic pain. IVD intervertebral disc, TNF- $\alpha$ tumor necrosis factor $\alpha$, LMP-1 LIM mineralization protein-1, SHOX2 short stature homeobox 2, TGF- $\beta$ transforming growth factor $\beta$, GDF growth and differentiation factor, IL-1Ra IL-1 receptor antagonist

relieves pain behaviors in a rat model. ${ }^{131}$ This study indicated that the TGF- $\beta 1$ and ERK1/2 MAPK signaling pathways may serve as therapeutic targets for the cure of inflammation-related pain associated with IVDD. ${ }^{131}$

\section{TLR signaling}

TLRs, an integral part of the innate immune system, are activated by pathogen-associated molecular patterns, such as bacterial cell wall debris. $^{138}$ It has been reported that TLRs 1, 2, 4, and 6 are expressed by disc cells and correlate with the severity of disc degeneration. ${ }^{139}$ Krock et al. found that TLR2 activation induces NGF and BDNF gene expression and NGF protein secretion in human IVD cells, which could be used to target NGF to treat LBP associated with disc degeneration. ${ }^{132}$ Recently, the same group showed that chronic TLR4 inhibition alleviated behavioral signs of LBP, pain-related neuroplasticity, and disc inflammation in SPARC-null mice. ${ }^{41}$ In addition, TAK242 inhibits TLR4 activation in the IVDs and significantly reduces cytokine release. ${ }^{41} \mathrm{Li}$ et al. showed that resistin bound directly to TLR4 and increased CCL4 expression in NP cells via the p38-MAPK and NF-KB pathways, which ultimately led to macrophage infiltration. ${ }^{140}$ It has also been reported that high mechanical loading not only promotes the secretion of inflammatory and pain-related factors of IVD cells, such as TNF- $a$, IL-6, IL-8, IL-17, IFN- - , monocyte chemoattractant protein 1 (MCP-1), and NGF, but also upregulates TLR2 and TLR4 expression, indicating that mechanical stress may play important roles in inducing and maintaining discogenic LBP. ${ }^{141,142}$ Therefore, TLRs are potential therapeutic targets to cure disc degeneration and reduce discogenic pain.

\section{MOLECULES UNDER LABORATORY INVESTIGATION TO TARGET INFLAMMATION AND DISCOGENIC PAIN}

Since inflammation plays a vital role in the production of discogenic LBP, various molecules, and chemicals have been investigated by researchers worldwide for their potential to suppress inflammation and related discogenic pain, as summarized in Fig. 4.

\section{TNF-a inhibitors}

TNF- $\alpha$ is an important cytokine involved in inflammatory signaling. TNF-a inhibitors, including infliximab and atsttrin, have been shown to suppress inflammation and pain. Infliximab is an anti-TNF-a antibody. When injected intradiscally in rats, infliximab reduced pain to sham levels. ${ }^{39}$ Atsttrin is a synthesized protein containing three fragments of progranulin, a growth factor implicated in inflammation.
This protein can bound directly to TNF-a receptors and antagonized TNF-a-initiated inflammatory signaling in a mouse model of multiple arthritis. ${ }^{143}$ In ex vivo cultured murine and human discs, atsttrin also decreased TNF- $\alpha$-triggered inflammatory cytokine production (MMP13, COX-2, iNOS, and IL-17) and subsequent catabolic changes, including loss of cartilage, disc height, and NP cells. ${ }^{86}$ Due to its long half-life, high efficacy, low molecular weight and no oncogenic effect over progranulin, atsttrin warrants further investigation in the management of inflammatory IDD.

\section{IL-1 inhibitors}

IL-1 receptor antagonist (IL-1Ra) is a natural inhibitor of IL-1. This molecule binds to the IL-1 receptor (IL-1R), thus preventing the binding of IL-1 to IL-1R and the delivery of inflammatory signals. IL-1Ra knockout in mice led to accelerated IDD, represented by decreased proteoglycan, disrupted collagen structure, increased matrix-degrading enzymes, including MMP3, MMP7, and ADAMTS4, ${ }^{144}$ and a higher histological grade of degeneration. IL-1Ra-deficient IVD cells also exhibited decreased proliferation. ${ }^{144}$ Further evidence showed that IL-1Ra might have a therapeutic effect on discogenic pain. Treatment of nondegenerated or degenerated human IVD explants with IL-1Ra reversed the catabolic effect of IL-1, including the expression of matrix degradation proteases, including type II collagenase, gelatinase, caseinase, and MMP3. Moreover, a single injection of IVD cells overexpressing IL-1Ra in the explants caused a significant inhibition of the expression of all matrix degradation enzymes, which could be sustained for 2 weeks. ${ }^{101}$

IL-4 is an anti-inflammatory cytokine. In macrophages, IL-4 inhibits the production of TNF- $\alpha$ and IL-1 $\beta$ and induces the secretion of IL$12 .^{145}$ In DRGs, overexpression of IL-4 ${ }^{146}$ suppressed pain-related behaviors, including mechanical allodynia and thermal hyperalgesia, and decreased c-Fos, a histologic marker of nociceptive processing in the dorsal horn. In addition, the upregulation of inflammatory cytokines, including PGE2 and IL-1 $\beta$, was retarded. ${ }^{146}$ In IVD cells, IL-4 treatment reduced inflammatory gene expression of IFN-beta, IL-12, IL-6, and IL-8 and downregulated the protein release of IL- 6 and IL-8 in LPS-treated IVD cells. ${ }^{147}$

Transforming growth factor beta (TGF- $\beta$ ) superfamily

TGF- $\beta$ is a group of proteins involved in the early regulation of cell growth and development. Among them, TGF- $\beta 1$, growth and differentiation factor 5 (GDF-5) and GDF- 6 have been shown to suppress inflammation in the IVD. 
TGF- $\beta 1$ can downregulate TNF- $\alpha$ expression induced by IFN- $\gamma$ and $\mathrm{IL}-1 \beta$ and antagonize collagen $\mathrm{I}$ and MMP3 expression induced by TNF- $a$ in NP cells. ${ }^{148}$ An in vivo study showed that intradiscal injection of TGF- $\beta 1$ downregulated CCL4 expression, prevented the inflammatory response and reduced degenerative features and pain behavior in rats with induced IDD. ${ }^{131}$ In a rat model of neuropathy, intrathecal infusion of TGF- $\beta 1$ significantly attenuated the development of pain hypersensitivity and reversed previously established pain. ${ }^{149}$ The effect of TGF- $\beta$ is reported to be exerted through ERK1/2 signaling, which could be abolished by specific inhibitors. ${ }^{148}$

GDF-5 is a protein involved in skeletal and joint development. GDF-5 gene polymorphism is associated with IDD susceptibility. ${ }^{150}$ GDF-5 deficiency in mice resulted in decreased proteoglycan and collagen II levels and abnormal histology in the IVD. ${ }^{151}$ In rat NP cells, ${ }^{152}$ GDF-5 overexpression inhibited the secretion of TNF-a, IL-1 $\beta$, PGE2, and NO in culture medium induced by LPS, inhibited the decrease in matrix production, including collagen II and aggrecan, and prevented NF-KB activation induced by LPS.

GDF-6 (BMP13) has an important role in early embryonic and spinal column development. ${ }^{153}$ Injection of GDF-6 in the early stages of IDD can prevent the loss of ECM proteins and retain greater hydration and cells in the NP. ${ }^{154}$ Clarke et al. found that GDF-6 can stimulate adipose-derived MSCs (AD-MSCs) to differentiate into NP-like cells. The differentiated AD-MSCs show an increase in aggrecan-to-type II collagen gene expression. ${ }^{155}$ GDF-6 also has the potential to enhance ECM accumulation and induce cell migration in certain disc cells. ${ }^{156}$ Miyazaki et al. found that the expression of TNF-a, IL-6, VEGF, COX-2, and NGF was significantly reduced by injecting GDF- 6 into a rabbit puncture model of IVD. GDF-6 injection had a certain effect on IDD and attenuated degenerated IVD-induced pain. ${ }^{157,158}$

\section{LIM mineralization protein-1 (LMP-1)}

LMP-1 regulates osteogenesis and chondrogenesis. Overexpression of LMP-1 increased, whereas knockdown of LMP-1 decreased, the production of ECM components, including collagen II, aggrecan, versican, and soluble $\mathrm{GAG}^{159,160}$ via ERK1/2 activation. ${ }^{160}$ Moreover, overexpression of LMP-1 abolished TNF-amediated MMP-3 and MMP-13 expression by inhibiting p65 translocation, as well as MMP-3 and MMP-13 promoter activity. ${ }^{160}$ These results indicated that LMP-1 has an anti-inflammatory effect against TNF- $a$ to maintain IVD possibly via ERK1/2 activation and NF-KB inhibition.

Short stature homeobox 2 (SHOX2)

SHOX2 is a member of the short stature homeobox gene family and is essential in skeletal development. In vivo human IDD or in vitro TNF-a treatment led to decreased expression of SHOX2. ${ }^{161}$ Treatment with SHOX2 siRNA inhibited the proliferation and apoptosis of NP cells, decreased aggrecan and collagen II expression, and increased MMP3 and ADAMTS- 5 production in NP cells. ${ }^{161}$ These results indicated that SHOX2 has a protective effect in the IVD and is worth further investigation.

\section{Melatonin}

Melatonin is a natural hormone in the body involved in biorhythm regulation. In the IVD, melatonin diminished cellular apoptosis caused by tert-butyl hydroperoxide, maintained ECM production, and suppressed the expression of degenerative enzymes, including MMP-13 and ADAMTS-5, in NP cells. ${ }^{162}$ The effect of melatonin is partially related to its activation of autophagy and mitophagy. Melatonin activated Parkin, the upstream regulator of mitophagy, in a dose and time-dependent manner in NP cells. Mitophagy inhibition by cyclosporine $\mathrm{A}$ partially eliminated the protective effects of melatonin. ${ }^{162}$ In vitro cell culture and in vivo rat model study showed that melatonin delayed the progression of IL-1 $\beta$-induced IVDD and related LBP via inhibiting the IL-1 $\beta / N F-K B-N L R P 3$ inflammasome activation positive feedback loop, and downregulating mitochondrial reactive oxygen species (mtROS) production, suggesting melatonin might be a considerable potential clinical agent for IVDD. ${ }^{163}$

\section{Resveratrol}

Resveratrol is a polyphenolic phytoalexin in red wine with an antioxidative effect. Dietary supplementation of grape polyphenol, which contained resveratrol, to rats with punctured discs reduced the behavioral sensitivity and gene expression levels of proinflammatory cytokines in DRGs but failed to alleviate disc degeneration or change the proinflammatory cytokine level in IVD. ${ }^{164}$ In vitro, resveratrol partially counteracted the inflammatory effects of TNF- $\alpha$ and IL-1 $\beta$, including decreased ECM content and increased NP cell senescence and matrix degradation enzymes (MMP-3, MMP-13, and ADAMTS-4). ${ }^{165}$ Resveratrol also showed a similar anticatabolic effect to reverse the matrix degradation and apoptotic induction of oxidative damage caused by hydrogen peroxide in NP cells. ${ }^{166}$ The effect may be mediated by the activation of autophagy ${ }^{165}$ through the PI3K/Akt pathway ${ }^{167}$ or AMPK/SIRT1 signaling pathway ${ }^{168}$ but does not seem to involve the MAP kinase pathways or the NF-KB/SIRT1 pathway. ${ }^{169}$ Furthermore, in a rodent model, resveratrol ameliorated pain behavior triggered by the application of NP tissue to the DRG. ${ }^{169}$ Overall, resveratrol seems to have a promising effect on the treatment of IVD-derived pain.

\section{Triptolide}

Triptolide is a natural substance found in the Chinese medicinal herb Tripterygium wilfordii Hook. A recent study ${ }^{170}$ demonstrated that triptolide at low concentrations $\left(50 \mathrm{nmol} \cdot \mathrm{L}^{-1}\right)$ had an antiinflammatory effect in human IVD cells by suppressing the expression of IL-6/-8, PGE2S, MMP1/2/3/13, and TLR2/4 and an anticatabolic effect on the production of aggrecan and collagen-II. However, a higher concentration of triptolide resulted in an upregulation of TNF-a, indicating its adverse effect at the high dose. It was further found that these effects of triptolide were achieved via the MAP kinases p38 and ERK but not via the JNK or NF-KB pathways. ${ }^{170}$

\section{Kaempferol}

Kaempferol is a natural flavonol found in many plants. In bone marrow MSCs, kaempferol decreased MMP3 and MMP13, alleviated LPS-induced inflammation by reducing the level of the proinflammatory cytokine IL- 6 and increasing anti-inflammatory cytokines such as IL-10 by inhibiting the nuclear translocation of NF-KB p65. ${ }^{171}$ However, since in the same study, ${ }^{171}$ kaempferol was shown to inhibit chondrogenesis while promoting the osteogenesis of bone marrow MSCs, a question might be raised regarding whether the application of kaempferol with MSCs may increase the risk of ectopic bone generation in IVDs.

\section{Sesamin}

Sesamin is a bioactive component extracted from sesame. Li et al. ${ }^{172}$ tested the effect of sesamin on LPS-induced IDD. These researchers reported that sesamin inhibited the activation of LPS-induced JNK but not p38 or ERK. As a result, this molecule effectively inhibited LPS-induced inflammatory factors (IL-1 $\beta$, TNFa, iNOS, NO, COX-2, and PGE2) and the production of catabolic enzymes (MMP-1, MMP-3, MMP-13, ADAMTS-4, and ADAMTS-5) in a dose-dependent manner in rat disc explants. Sesamin also blocked the LPS-induced migration of macrophages and the degradation of collagen II and aggrecan.

\section{Lactoferricin}

Lactoferricin is an amphipathic, cationic peptide derived from milk protein. Bovine lactoferricin has been shown to significantly attenuate the IL-1 $\beta$ and LPS-mediated suppression of proteoglycan 
production in human and bovine NP cells. ${ }^{173}$ Simultaneously, lactoferricin reduced multiple degrading enzymes, including MMP-1, MMP-3, MMP-13, ADAMTS-4, and ADAMTS-5, in bovine NP cells. ${ }^{173}$ In addition, lactoferricin suppresses oxidative and inflammatory factors, such as iNOS, IL-6, Toll-like receptor-2 (TLR-2), and TLR-4. ${ }^{173}$

\section{Coenzyme Q10 (Co-Q10)}

Co-Q10 is a coenzyme that plays a vital role in the electron transport chain. A recent study by Wang et al. ${ }^{174}$ suggested that Co-Q might have anti-inflammatory effects on IVDs. In IL$1 \beta$-treated human NP cells, the expression of inflammatory biomarkers, including TNF-a, COX-2, IL- 6 , and iNOS, was reduced by Co-Q10. Co-Q10 also helped to prevent the IL-1 $\beta$-induced reduction in collagen 2, aggrecan, and Sox-9. It was further postulated that the anti-inflammatory effect potentially occurs through the inhibition of NF-KB signaling activation, while the anabolic impact of Co-Q10 is possibly associated with the Akt activation signaling pathway.

\section{Urolithin A (UA)}

Urolithin A (UA) is a metabolite transformed from ellagitannins by gut bacteria. Recent studies have indicated UA has antiinflammatory and antioxidant properties. ${ }^{175,176}$ A 2018 study ${ }^{177}$ investigated the effect of UA treatment on IDD. UA ameliorated hydrogen peroxide-induced cell senescence and decreased the TNFa-induced reduction in collagen II and the production of MMP3 and MMP13 in NP cells. In a rat tail model, UA treatment alleviated the puncture-induced reduction in disc height, the increase in Pfirrmann grade scores and disc histological destruction. It was further revealed that UA inhibited ERK, JNK, and Akt phosphorylation but had no influence on the NF-KB p65 and p38-MAPK pathways.

In summary, LMP-1, kaempferol, Co-Q10, and possibly TNF- $a$ inhibitors and IL-1 inhibitors exert their effects by inhibiting NF-KB signaling. TGF- $\beta$ may also belong to this group, since TGF- $\beta$ can inhibit TNF- $\alpha$ and IL-1 $\beta$ secretion. LMP-1, triptolide and UA can mediate their effects through ERK1/2 activation, while lactoferricin suppresses TLR2/4. Triptolide also deactivates p38-MAPK. The majority of the above molecules showed anti-inflammatory effects and prevented disc matrix degradation. However, only a few of them, including TNF- $\alpha$ inhibitors, IL- 1 inhibitors, TGF- $\beta 1$, GDF- 6 and resveratrol, are effective in alleviating discogenic pain. The other discussed molecules can suppress inflammation, but whether they can regulate pain production awaits further study.

\section{CLINICAL TREATMENTS AND TRIALS SUPPRESSING INFLAMMATION TO TREAT DISCOGENIC LBP}

In this section, we focus on bioactive agents, which exert their pain-alleviating effects by suppressing inflammation, being tested in clinical trials.

\section{TNF-a inhibitors}

The clinical effect of TNF-a inhibitors on discogenic LBP has not been reported but has been investigated in disc-related diseases, such as sciatica (Table 2). In a clinical trial of treating severe sciatica with infliximab, Karppinen et al. ${ }^{178}$ found that the pain was significantly relieved at $1 \mathrm{~h}$ after the injection, and there was no need for surgery at 3 months of follow-up. Cohen et al. ${ }^{179}$ performed a double-blinded trial to investigate epidural etanercept, an anti-TNF-a medication, in the treatment of sciatica. One month after treatment, etanercept delivered significant improvements in leg and back pain, with $17 \%$ in the saline group, $100 \%$ in the $2 \mathrm{mg}$ group, and $67 \%$ each in the $4 \mathrm{mg}$ and $6 \mathrm{mg}$ groups reporting at least a $50 \%$ reduction in leg pain and a positive global perceived effect, which persisted for 6 months after treatment. Currently, a clinical trial investigating the effect of infliximab in treating chronic LBP and modic changes is recruiting patients. ${ }^{180}$
Platelet-rich plasma (PRP)

PRP has been reported to alleviate inflammation and pain in various systems. ${ }^{181,182}$ PRP contains a cocktail of growth factors, such as platelet-derived growth factor, TGF- $\beta$, epidermal growth factor, insulin-like growth factor 1 and vascular endothelial growth factor. It also contains blood-clotting factors and proteinase inhibitors. It is possible that the complex ingredients in PRP together exert multiple effects to dampen inflammation and promote tissue regeneration. For example, we know from our previous analysis that TGF- $\beta$ plays a role in suppressing painful disc degeneration.

PRP has been clinically investigated as a biologic therapy to stimulate disc regeneration or at least delay disc degeneration (Table 2). In 2011, Akeda et al. injected six LBP patients with $2 \mathrm{~mL}$ of PRP. ${ }^{183}$ The results showed that the mean pain scores decreased from 7.1 to 1.8 on a numeric rating scale (NRS) at 1 month, and this effect was maintained at 6 months, although there was no change in mean T2 values. Later, the same group injected 14 LBP patients with $2 \mathrm{~mL}$ of PRP. ${ }^{184}$ The results showed that the mean pain scores on a NRS decreased from 7.5 at 1 month to 2.9 at 12 months, and the RDQ decreased from 12.6 at 1 month to 2.8 at 12 months. ${ }^{184}$ In another clinical study, Levi et al. $^{185}$ studied the safety and feasibility of intravertebral disc injection of PRP to treat disc degeneration. The study included 22 patients with disc herniation. Each treated disc received an injection of $1.5 \mathrm{~mL}$ of PRP into the center of the NP under dioptric guidance. An unqualified success was defined as at least a $50 \%$ improvement in the VAS and a $30 \%$ decrease in the ODI. A total of $14 \%, 32 \%$, and $47 \%$ of the patients achieved a successful outcome at 1, 2, and 6 months, respectively, while the percentages reaching a $50 \%$ decrease in VAS were $36 \%, 41 \%$, and $47 \%$, respectively, demonstrating a satisfactory effect. In 2016, a prospective randomized controlled trial enrolled 47 patients for the application of PRP to treat discogenic LBP. ${ }^{186}$ Twenty-nine patients received PRP injection, while 18 patients received contrast agent only. The improvement of patients' LBP symptoms and function occurred as early as 8 weeks after treatment, and the effect could be maintained for at least one year. No adverse events were observed. In 2017, Lutz $^{187}$ reported a clinical case in which intradiscal injection of $1.5 \mathrm{~mL}$ of autologous PRP improved the symptoms of an LBP patient who returned to athletic activities as early as 6 weeks after the surgery. This case is the only one to show improved MRI signals by PRP injection.

In summary, the current studies consistently supported the safety and efficiency of PRP treatment in relieving disc pain and function.

\section{NGF inhibitors}

NGF regulates painful nerve activity and plays a vital role in pain signaling pathways. ${ }^{188}$ Katz et al. ${ }^{189}$ compared the remission of symptoms in patients with chronic nonradiculopathic pain treated with tanezumab, a monoclonal antibody with a high affinity for NGF, by intravenous injection. In total, 88 patients received tanezumab $\left(200 \mu \mathrm{g} \cdot \mathrm{kg}^{-1}\right), 88$ patients received placebo plus oral naproxen $500 \mathrm{mg}$ twice a day, and 41 patients received placebo. After 6 weeks, the patients receiving tanezumab experienced a significant reduction in LBP compared to that of the other two groups. Tanezumab caused no serious adverse events but temporal and mild adverse events of abnormal peripheral sensation. Another follow-up trial with 1347 patients ${ }^{190}$ investigated the long-term safety and efficacy of different doses of tanezumab for chronic LBP and reported that tanezumab at 10 and $20 \mathrm{mg}$ had a similar effect in resolving pain and disability. However, tanezumab at various doses caused higher adverse events than placebo or naproxen. These events included arthralgia, pain in extremity, headache, and paresthesia, which resulted in the temporary termination of this trial. ${ }^{190}$ Later, an extension report from the same group ${ }^{191}$ included 321 patients for the $10 \mathrm{mg}$ dose and 527 patients for the $20 \mathrm{mg}$ dose administered 
Table 2. Biological treatments under clinical development to treat discogenic LBP

\begin{tabular}{|c|c|c|c|c|c|c|c|c|}
\hline Therapeutics & Authors & Year & $\begin{array}{l}\text { Number of } \\
\text { patients }\end{array}$ & Study design & Treatment & Analysis variables & $\begin{array}{l}\text { Follow- } \\
\text { up period }\end{array}$ & Outcomes \\
\hline PRP & $\begin{array}{l}\text { Akeda } \\
\text { et al. }\end{array}$ & 2011 & 6 & $\begin{array}{l}\text { Prospective } \\
\text { single arm }\end{array}$ & $\begin{array}{l}\text { Intradiscal } \\
\text { injection of } \\
1.5 \mathrm{~mL} \text { of PRP }\end{array}$ & VAS, RDQ, MRI (T2) & $6 \mathrm{M}$ & $\begin{array}{l}\text { VAS and RDQ were decreased at } \\
1 \text { month and sustained for } \\
6 \text { months. No change in T2 values } \\
\text { was observed. }\end{array}$ \\
\hline PRP & $\begin{array}{l}\text { Tuakli- } \\
\text { Wosornu } \\
\text { et al. }{ }^{186}\end{array}$ & 2016 & 47 & $\begin{array}{l}\text { Prospective } \\
\text { double- } \\
\text { blind RCT }\end{array}$ & $\begin{array}{l}\text { Intradiscal } \\
\text { injection of } \\
1-2 \mathrm{~mL} \text { of PRP } \\
(n=29) \text { vs. } \\
\text { contrast agent } \\
(n=18)\end{array}$ & $\begin{array}{l}\text { FRI, NRS, 36-item } \\
\text { Short Form Health } \\
\text { Survey, and } \\
\text { modified NASS } \\
\text { Outcome } \\
\text { Questionnaire }\end{array}$ & $12 \mathrm{M}$ & $\begin{array}{l}\text { The improvement of patients' } \\
\text { LBP symptoms and function } \\
\text { occurred as early as } 8 \text { weeks after } \\
\text { treatment and was maintained } \\
\text { for at least } 1 \text { year. }\end{array}$ \\
\hline PRP & $\begin{array}{l}\text { Levi } \\
\text { et al. }\end{array}$ & 2016 & 22 & Single arm & $\begin{array}{l}\text { Intradiscal } \\
\text { injection of } \\
1.5 \mathrm{~mL} \text { of PRP } \\
\text { at one or } \\
\text { more levels }\end{array}$ & VAS, ODI & $6 M$ & $\begin{array}{l}14 \%, 32 \% \text {, and } 47 \% \text { of the } \\
\text { patients achieved a successful } \\
\text { outcome at } 1,2 \text {, and } 6 \text { months, } \\
\text { while the percentages reaching a } \\
50 \% \text { decrease in VAS were } 36 \% \text {, } \\
41 \% \text {, and } 47 \% \text {. }\end{array}$ \\
\hline PRP & $\begin{array}{l}\text { Akeda } \\
\text { et al. }\end{array}$ & 2017 & 14 & $\begin{array}{l}\text { Prospective } \\
\text { single arm }\end{array}$ & $\begin{array}{l}\text { Intradiscal } \\
\text { injection of } \\
2 \mathrm{~mL} \text { of PRP }\end{array}$ & $\begin{array}{l}\text { VAS, RDQ, X-ray, } \\
\text { MRI (T2) }\end{array}$ & $12 \mathrm{M}$ & $\begin{array}{l}\text { The mean pain scores before } \\
\text { treatment (VAS: } 7.5 \pm 1.3 ; \text { RDQ: } \\
12.6 \pm 4.1 \text { ) were decreased at } \\
1 \text { month and were sustained at } \\
6 \text { months (VAS, } 3.2 \pm 2.4, \text { RDQ; } \\
3.6 \pm 4.5 \text { ) and } 12 \text { months (VAS, } \\
2.9 \pm 2.8 ; \text { RDQ, } 2.8 \pm 3.9 \text { ) after } \\
\text { treatment. } \\
\text { No significant changes in the } \\
\text { mean T2 values was observed. }\end{array}$ \\
\hline $\begin{array}{l}\text { TNF- } \alpha \\
\text { inhibitors }\end{array}$ & $\begin{array}{l}\text { Karppinen } \\
\text { et al. }{ }^{178}\end{array}$ & 2003 & 72 & $\begin{array}{l}\text { Open-label, } \\
\text { controlled } \\
\text { study to treat } \\
\text { sciatica }\end{array}$ & $\begin{array}{l}\text { Infliximab } \\
(3 \mathrm{mg}, n=10) \\
\text { vs. saline }(n= \\
62)\end{array}$ & $\begin{array}{l}\text { VAS, ODQ, MRI (T2 } \\
\text { and T1), SLR, } \\
\text { Schober }\end{array}$ & $3 M$ & $\begin{array}{l}\text { The infliximab group had more } \\
\text { pain reduction than the control } \\
\text { group (painless patients after } \\
2 \text { weeks: } 60 \% \text { vs. } 16 \% \text {; after } \\
3 \text { months: } 90 \% \text { vs. } 46 \% \text { ). At } \\
1 \text { month, all patients in the } \\
\text { infliximab group went back to } \\
\text { work, while } 38 \% \text { in the control } \\
\text { group remained on sick leave. }\end{array}$ \\
\hline $\begin{array}{l}\text { TNF- } \alpha \\
\text { inhibitors }\end{array}$ & - & 2018 & 126 & $\begin{array}{l}\text { RCT double } \\
\text { blind, } \\
\text { multicenter }\end{array}$ & $\begin{array}{l}\text { Infliximab vs. } \\
\text { placebo }\end{array}$ & ODI, NRS, STIR, RDQ & $9 \mathrm{M}$ & $\begin{array}{l}\text { Recruiting (Clinical trial ID: } \\
\text { NCT03704363) }\end{array}$ \\
\hline $\begin{array}{l}\text { NGF } \\
\text { inhibitors }\end{array}$ & $\begin{array}{l}\text { Katz } \\
\text { et al. }\end{array}$ & 2011 & 217 & $\begin{array}{l}\text { RCT double- } \\
\text { blind, } \\
\text { multicenter, } \\
\text { parallel }\end{array}$ & $\begin{array}{l}\text { Tanezumab } \\
(n=88), \\
\text { naproxen }(n= \\
88) \text { or placebo } \\
(n=41)\end{array}$ & $\begin{array}{l}\text { aLBPI, RDQ, BPI-SF, } \\
\text { PGA, Patients' } \\
\text { Global Evaluation, } \\
\text { rescue } \\
\text { medication use }\end{array}$ & $6 \mathrm{~W}$ & $\begin{array}{l}\text { The tanezumab group had a } \\
\text { better reduction in aLBPI, RDQ } \\
\text { and other secondary outcomes, } \\
\text { except rescue medication use, } \\
\text { than the naproxen or } \\
\text { placebo group. }\end{array}$ \\
\hline $\begin{array}{l}\text { NGF } \\
\text { inhibitors }\end{array}$ & $\begin{array}{l}\text { Kivitz } \\
\text { et al. }{ }^{190}\end{array}$ & 2013 & 1347 & $\begin{array}{l}\mathrm{RCT} \text {, double- } \\
\text { blind, } \\
\text { multicenter, } \\
\text { parallel } \\
\text { phase IIB }\end{array}$ & $\begin{array}{l}\text { Tanezumab }(5, \\
10, \text { or } 20 \mathrm{mg}), \\
\text { naproxen } \\
(500 \mathrm{mg}), \text { or } \\
\text { placebo }\end{array}$ & aLBPI, RDQ, PGA & $16 \mathrm{~W}$ & $\begin{array}{l}\text { Tanezumab at } 10 \text { and } 20 \mathrm{mg} \text { had } \\
\text { a similar efficacy in improving } \\
\text { aLBPI, RDQ, and the PGA scores } \\
\text { vs. both placebo and naproxen. } \\
\text { Tanezumab at } 5 \text { mg improved the } \\
\text { PGA scores vs. placebo. } \\
\text { Arthralgia, pain in extremity, }\end{array}$ \\
\hline
\end{tabular}




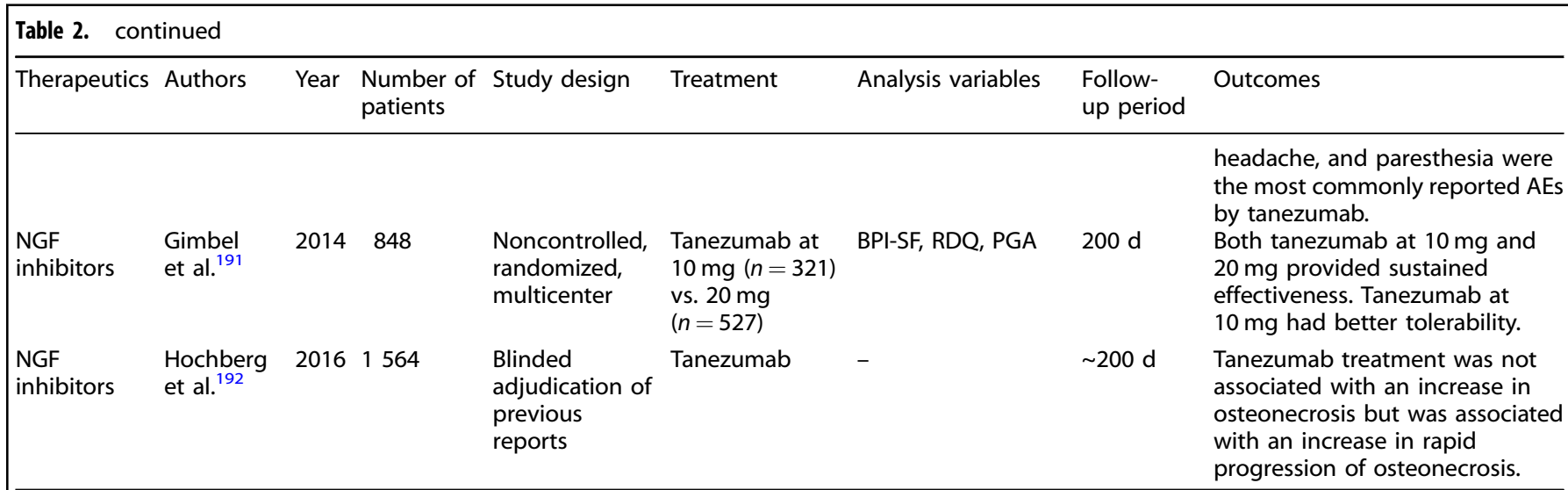

NRS numeric rating scale, VAS visual analog scale, $O D I$ Oswestry disability index, $R D Q$ Roland-Morris disability questionnaire, $F R I$ functional rating index, $R C T$ randomized controlled trial, aLBPI average LBP intensity, STIR short tau inversion recovery, PGA patient's global assessment, AEs adverse events, NASS North American Spine Society, SLR straight-leg-raising test, BPI-SF brief pain inventory-short form

intravenously for an average 200 days at 8-week intervals. Both doses showed a similar effect in LBP relief. The majority of adverse effects included arthralgia, paresthesia, and hypoesthesia. Osteonecrosis was also observed. It was concluded that the $10 \mathrm{mg}$ dose was better tolerated than the $20 \mathrm{mg}$ dose. However, blinded adjudication of the above studies $^{192}$ revealed that osteonecrosis was not primary in these cases, but tanezumab treatment was associated with an increase in the rapid progression of osteoarthritis.

Overall, it was concluded from the above studies that treatment with $10 \mathrm{mg}$ tanezumab met the primary endpoint, demonstrating a significant improvement in pain at 16 weeks compared to placebo, and the adverse reactions were not severe.

\section{DISCUSSION}

Disc degeneration is a common phenomenon in the aged population and has a complex etiology. Painful disc degeneration is a major contribution to LBP, during which persistent inflammation is thought to be an important factor. ${ }^{8,15}$ In this review, we focused on the contribution of inflammation to disc degeneration and the associated LBP. We reviewed laboratory studies on potential candidate molecules to treat disc degeneration by dampening inflammation and summarized the current progress of clinical trials targeting inflammation and discogenic pain.

Among the laboratory studies on IVD regeneration, we focused on those that investigated the effect of the target molecule on suppressing IVD inflammation and pain. These anti-inflammatory molecule candidates include TNF- $\alpha$ inhibitors, IL-1Ra, IL-4, TGF- $\beta 1$, LMP-1, SHOX2, GDF-6, lactoferricin, triptolide, kaempferol, Co-Q10, $U A$, and sesamin, with a focus on the inhibition of TNF- $\alpha$ and IL-1 $\beta$. These molecules all have the potential for future drug development to treat painful disc degeneration, providing a full understanding of their effect and underlying mechanism. However, among these, only TNF- $\alpha$ inhibitors, IL- 1 inhibitors, TGF- $\beta 1$, GDF-6, and resveratrol have been demonstrated to be effective in alleviating discogenic pain. The effect of the others on pain suppression awaits further study.

Despite showing potential in laboratory tests, many antiinflammatory molecules explored in the laboratory, as mentioned above, have not yet been used in clinical investigation, possibly because only a few laboratory studies have been conducted on these molecules. Therefore, there are insufficient exploratory and repeated studies to support a wide recognition of these molecules for their potential in painful disc treatment. Further studies, which assess safety and efficacy, will be necessary before these molecules can be used as drugs. To date, the potential therapies under clinical investigation to treat LBP include TNF- $a$ inhibitors, PRP, and NGF inhibitors. These reagents have unique advantages in clinical development in that they are established in the treatment of other diseases. The delivery methods include intravertebral disc injection or intravenous infusion. The majority of these trials demonstrated promising efficacy in alleviating pain and restoring spinal motion. However, since the follow-up time is limited, it is not clear whether these treatments are effective for a long period of time. In addition, most trials focused on pain assessment without assessing or showing any effect on the biological repair of IVDs, and only one trial among these detected IVD restorations, as represented by an improved MRI T2 signal. Therefore, evidence of these drugs in IVD repair is still lacking, and it is also unclear whether the treatment affects the natural process of IDD. More importantly, although the timing of the intervention has not been investigated in these studies, this factor might have a significant impact on the outcome of the treatment, as less degenerated discs could be easier to regenerate, while severely deranged discs are hard to repair. ${ }^{193}$ In addition, psychological factors may play a role in some unexplained back pain, which makes it difficult to assess and identify appropriate patients for treatment.

Currently, the majority of studies on IVD have focused on NP and AF with less emphasis on EP and subchondral bone. ${ }^{75,194}$ However, the IVD is an integrated tissue with three parts closely interacting with each other to constitute the structure, function and metabolism. The EP seals the NP and contains the main diffusion channel of nutrients into the IVD, and EP damage or calcification can alter the biomechanical behaviors, pattern and nutrient supply as a pain generator or accelerator of IDD. Few studies have explored the degeneration of EP and subchondral bone and reported its association with pain introduction. Encouragingly, some recent studies have taken one step forward. For example, Lv et al., ${ }^{195}$ Bailey et al., ${ }^{196}$ and Munir et al. ${ }^{197}$ independently reported that the grade of EP defects positively correlated with the grade of IDD or chronic LBP. More studies are needed in this field. More importantly, treating IVD as a whole instead of three isolated sections may be the future direction and provide novel insights into the treatment of painful IVD.

\section{ACKNOWLEDGEMENTS}

This study was supported by the National Natural Science Foundation of China (81772386, 81702191, 81572175, 81371984, and 81071511), the Guangdong-Hong Kong Joint Innovation Project of Guangdong Province (2017A050506019), and the Natural Science Foundation of Guangdong Province, China (2020A1515011031). 


\section{ADDITIONAL INFORMATION}

Competing interests: The authors declare no competing interests.

\section{REFERENCES}

1. Hartvigsen, J. et al. What low back pain is and why we need to pay attention. Lancet 391, 2356-2367 (2018).

2. Jackson, T. et al. Prevalence of chronic pain in low-income and middle-income countries: a systematic review and meta-analysis. Lancet 385, S10 (2015).

3. Buchbinder, R. et al. Low back pain: a call for action. Lancet 391, 2384-2388 (2018).

4. Foster, N. E. et al. Prevention and treatment of low back pain: evidence, challenges, and promising directions. Lancet 391, 2368-2383 (2018).

5. Maher, C., Underwood, M. \& Buchbinder, R. Non-specific low back pain. Lancet 389, 736-747 (2017)

6. Cheung, K. M. et al. Prevalence and pattern of lumbar magnetic resonance imaging changes in a population study of one thousand forty-three individuals. Spine 34, 934-940 (2009).

7. Wuertz, K. \& Haglund, L. Inflammatory mediators in intervertebral disk degeneration and discogenic pain. Glob. Spine J. 3, 175-184 (2013).

8. Risbud, M. V. \& Shapiro, I. M. Role of cytokines in intervertebral disc degeneration: pain and disc content. Nat. Rev. Rheumatol. 10, 44 (2014).

9. Adams, M. A. \& Roughley, P. J. What is intervertebral disc degeneration, and what causes it? Spine 31, 2151-2161 (2006).

10. Richardson, S. M. et al. Degenerate human nucleus pulposus cells promote neurite outgrowth in neural cells. PloS ONE 7, e47735 (2012).

11. Stefanakis, M. et al. Annulus fissures are mechanically and chemically conducive to the ingrowth of nerves and blood vessels. Spine 37, 1883-1891 (2012).

12. Khan, A. N. et al. Inflammatory biomarkers of low back pain and disc degeneration: a review. Ann. N.Y. Acad. Sci. 1410, 68-84 (2017)

13. Navone, S. E. et al. Inflammatory mediators and signalling pathways controlling intervertebral disc degeneration. Histol. Histopathol. 32, 523-542 (2017).

14. Cunha, $C$. et al. The inflammatory response in the regression of lumbar disc herniation. Arthritis Res. Ther. 20, 251 (2018).

15. Molinos, M. et al. Inflammation in intervertebral disc degeneration and regeneration. J. R. Soc. Interface 12, 20141191 (2015).

16. Vo, N. V. et al. Molecular mechanisms of biological aging in intervertebral discs. J. Orthop. Res. 34, 1289-1306 (2016).

17. Rodrigues-Pinto, R., Richardson, S. M. \& Hoyland, J. A. An understanding of intervertebral disc development, maturation and cell phenotype provides clues to direct cell-based tissue regeneration therapies for disc degeneration. Eur. Spine J. 23, 1803-1814 (2014).

18. Lyu, F. J. et al. IVD progenitor cells: a new horizon for understanding disc homeostasis and repair. Nat. Rev. Rheumatol. 15, 102-112 (2019).

19. Yang, F., Leung, V. Y., Luk, K. D., Chan, D. \& Cheung, K. M. Injury-induced sequential transformation of notochordal nucleus pulposus to chondrogenic and fibrocartilaginous phenotype in the mouse. J. Pathol. 218, 113-121 (2009).

20. Lv, F. J. et al. Matrix metalloproteinase 12 is an indicator of intervertebral disc degeneration co-expressed with fibrotic markers. Osteoarthr. Cartil. 24, 1826-1836 (2016)

21. Vasiliadis, E. S., Pneumaticos, S. G., Evangelopoulos, D. S. \& Papavassiliou, A. G. Biologic treatment of mild and moderate intervertebral disc degeneration. Mol. Med. 20, 400-409 (2014).

22. Huang, Y. C., Urban, J. P. \& Luk, K. D. Intervertebral disc regeneration: do nutrients lead the way? Nat. Rev. Rheumatol. 10, 561-566 (2014).

23. Bian, Q. et al. Excessive activation of TGF $\beta$ by spinal instability causes vertebral endplate sclerosis. Sci. Rep. 6, 27093 (2016).

24. Pandit, P., Talbott, J. F., Pedoia, V., Dillon, W. \& Majumdar, S. T1 $\rho$ and T2-based characterization of regional variations in intervertebral discs to detect early degenerative changes. J. Orthop. Res. 34, 1373-1381 (2016).

25. Arnbak, B. et al. Identification of subgroups of inflammatory and degenerative MRI findings in the spine and sacroiliac joints: a latent class analysis of 1037 patients with persistent low back pain. Arthritis Res. Ther. 18, 237 (2016).

26. Middendorp, M. et al. Association between intervertebral disc degeneration and the Oswestry Disability Index. J. Back Musculoskelet. Rehabil. 30, 819-823 (2017).

27. Arnbak, B. et al. Prevalence of degenerative and spondyloarthritis-related magnetic resonance imaging findings in the spine and sacroiliac joints in patients with persistent low back pain. Eur. Radiol. 26, 1191-1203 (2016).

28. Shamji, M. F. et al. Proinflammatory cytokine expression profile in degenerated and herniated human intervertebral disc tissues. Arthritis Rheum. 62, 1974-1982 (2010).

29. Ohtori, S., Inoue, G., Miyagi, M. \& Takahashi, K. Pathomechanisms of discogenic low back pain in humans and animal models. Spine J. 15, 1347-1355 (2015).

30. García-Cosamalón, J. et al. Intervertebral disc, sensory nerves and neurotrophins: who is who in discogenic pain? J. Anat. 217, 1-15 (2010).
31. Coppes, M., Marani, E., Thomeer, R., Oudega, M. \& Groen, G. Innervation of annulus fibrosis in low back pain. Lancet 336, 189-190 (1990).

32. Freemont, A. et al. Nerve ingrowth into diseased intervertebral disc in chronic back pain. Lancet 350, 178-181 (1997).

33. Ohtori, S., Miyagi, M. \& Inoue, G. Sensory nerve ingrowth, cytokines, and instability of discogenic low back pain: a review. Spine Surg. Relat. Res. 2, 11-17 (2018).

34. Lama, P., Le Maitre, C. L., Harding, I. J., Dolan, P. \& Adams, M. A. Nerves and blood vessels in degenerated intervertebral discs are confined to physically disrupted tissue. J. Anat. 233, 86-97 (2018).

35. Miyagi, M. et al. ISSLS Prize winner: Increased innervation and sensory nervous system plasticity in a mouse model of low back pain due to intervertebral disc degeneration. Spine 39, 1345-1354 (2014).

36. Ohtori, S. et al. Tumor necrosis factor-immunoreactive cells and PGP 9.5immunoreactive nerve fibers in vertebral endplates of patients with discogenic low back Pain and Modic Type 1 or Type 2 changes on MRI. Spine 31, 1026-1031 (2006).

37. Hayashi, S. et al. TNF-alpha in nucleus pulposus induces sensory nerve growth: a study of the mechanism of discogenic low back pain using tnf-alpha-deficient mice. Spine 33, 1542-1546 (2008).

38. Alimasi, W. et al. Regulation of nerve growth factor by anti-inflammatory drugs, a steroid, and a selective cyclooxygenase 2 inhibitor in human intervertebral disc cells stimulated with interleukin-1. Spine 38, 1466-1472 (2013).

39. Evashwick-Rogler, T. W. et al. Inhibiting tumor necrosis factor-alpha at time of induced intervertebral disc injury limits long-term pain and degeneration in a rat model. JOR Spine 1, e1014 (2018).

40. Edgar, M. The nerve supply of the lumbar intervertebral disc. J. Bone Jt. Surg. Br 89, 1135-1139 (2007).

41. Krock, E., Millecamps, M., Currie, J. B., Stone, L. S. \& Haglund, L. Low back pain and disc degeneration are decreased following chronic toll-like receptor 4 inhibition in a mouse model. Osteoarthr. Cartil. 26, 1236-1246 (2018).

42. Mosley, G. E., Evashwick-Rogler, T. W., Lai, A. \& latridis, J. C. Looking beyond the intervertebral disc: the need for behavioral assays in models of discogenic pain. Ann. N. Y. Acad. Sci. 1409, 51-66 (2017).

43. Yang, G., Liao, W., Shen, M. \& Mei, H. Insight into neural mechanisms underlying discogenic back pain. J. Int. Med. Res. 46, 4427-4436 (2018).

44. Fenty, M. et al. Novel imaging of the intervertebral disk and pain. Glob. Spine J. $\mathbf{3}$, 127-132 (2013).

45. Boden, S. D. et al. Abnormal magnetic-resonance scans of the cervical spine in asymptomatic subjects. A prospective investigation. J. Bone Jt. Surg. Am. 72, 1178-1184 (1990)

46. Vanharanta, H. et al. Pain provocation and disc deterioration by age. A CT/discography study in a low-back pain population. Spine 14, 420-423 (1989).

47. Peng, Y. \& Lv, F.-J. Symptomatic versus asymptomatic intervertebral disc degeneration: is inflammation the key? Crit. Rev. Eukaryot. Gene Expr. 25, 13-21 (2015).

48. Cho, H. et al. Snapshot of degenerative aging of porcine intervertebral disc: a model to unravel the molecular mechanisms. Exp. Mol. Med. 43, 334-340 (2011).

49. Melrose, J. et al. Mechanical destabilization induced by controlled annular incision of the intervertebral disc dysregulates metalloproteinase expression and induces disc degeneration. Spine 37, 18-25 (2012).

50. Zhang, Y. et al. Histological features of the degenerating intervertebral disc in a goat disc-injury model. Spine 36, 1519-1527 (2011).

51. Ganey, T., Hutton, W. C., Moseley, T., Hedrick, M. \& Meisel, H.-J. Intervertebral disc repair using adipose tissue-derived stem and regenerative cells: experiments in a canine model. Spine 34, 2297-2304 (2009).

52. Olmarker, K. Puncture of a lumbar intervertebral disc induces changes in spontaneous pain behavior: an experimental study in rats. Spine 33, 850-855 (2008).

53. Nilsson, E., Nakamae, T. \& Olmarker, K. Pain behavior changes following disc puncture relate to nucleus pulposus rather than to the disc injury per se: an experimental study in rats. Open Orthop. J. 5, 72-77 (2011).

54. Kim, J.-S. et al. The rat intervertebral disk degeneration pain model: relationships between biological and structural alterations and pain. Arthritis Res. Ther. 13, R165 (2011).

55. Lee, M. et al. Complete Freund's adjuvant-induced intervertebral discitis as an animal model for discogenic low back pain. Anesth. Analg. 109, 1287-1296 (2009).

56. Lai, A. et al. Assessment of functional and behavioral changes sensitive to painful disc degeneration. J. Orthop. Res. 33, 755-764 (2015).

57. Lai, A. et al. Annular puncture with tumor necrosis factor-alpha injection enhances painful behavior with disc degeneration in vivo. Spine J. 16, 420-431 (2016).

58. Millecamps, M. \& Stone, L. S. Delayed onset of persistent discogenic axial and radiating pain after a single-level lumbar intervertebral disc injury in mice. Pain 159, 1843-1855 (2018). 
59. Isa, I. L. M. et al. Implantation of hyaluronic acid hydrogel prevents the pain phenotype in a rat model of intervertebral disc injury. Sci. Adv. 4, eaaq0597 (2018).

60. Lee, S., Millecamps, M., Foster, D. Z. \& Stone, L. S. Long-term histological analysis of innervation \& macrophage infiltration in a mouse model of intervertebral disc injury-induced low back pain. J. Orthop. Res. 38, 1238-1247 (2020).

61. Li, Z. et al. Both expression of cytokines and posterior annulus fibrosus rupture are essential for pain behavior changes induced by degenerative intervertebral disc: an experimental study in rats. J. Orthop. Res. 32, 262-272 (2014).

62. Holguin, N., Martin, J. T., Elliott, D. M. \& Judex, S. Low-intensity vibrations partially maintain intervertebral disc mechanics and spinal muscle area during deconditioning. Spine J. 13, 428-436 (2013).

63. Ao, X. et al. Development and characterization of a novel bipedal standing mouse model of intervertebral disc and facet joint degeneration. Clin. Orthop. Relat. Res. 477, 1492-1504 (2019).

64. Hirata, H. et al. A rat tail temporary static compression model reproduces different stages of intervertebral disc degeneration with decreased notochordal cell phenotype. J. Orthop. Res. 32, 455-463 (2014).

65 . Wuertz, K. et al. In vivo remodeling of intervertebral discs in response to shortand long-term dynamic compression. J. Orthop. Res. 27, 1235-1242 (2009).

66. Lotz, J. C., Colliou, O. K., Chin, J. R., Duncan, N. A. \& Liebenberg, E. Compressioninduced degeneration of the intervertebral disc: an in vivo mouse model and finite-element study. Spine 23, 2493-2506 (1998).

67. Stokes, I. A., McBride, C. A., Aronsson, D. D. \& Roughley, P. J. Metabolic effects of angulation, compression, and reduced mobility on annulus fibrosis in a model of altered mechanical environment in scoliosis. Spine Deform. 1, 161-170 (2013).

68. Ariga, K. et al. The relationship between apoptosis of endplate chondrocytes and aging and degeneration of the intervertebral disc. Spine 26, 2414-2420 (2001).

69. Chubinskaya, S. et al. Anti-catabolic effect of OP-1 in chronically compressed intervertebral discs. J. Orthop. Res. 25, 517-530 (2007).

70. Miyagi, M. et al. ISSLS prize winner: disc dynamic compression in rats produces long-lasting increases in inflammatory mediators in discs and induces long-lasting nerve injury and regeneration of the afferent fibers innervating discsa pathomechanism for chronic discogenic low back pain. Spine 37, 1810-1818 (2012).

71. Suzuki, M. et al. Vertebral compression exacerbates osteoporotic pain in an ovariectomy-induced osteoporosis rat model. Spine 38, 2085-2091 (2013).

72. Fukui, D. et al. Gait abnormality due to spinal instability after lumbar facetectomy in the rat. Eur. Spine J. 24, 2085-2094 (2015).

73. Fukui, D. et al. Three-dimensional micro-computed tomography analysis for spinal instability after lumbar facetectomy in the rat. Eur. Spine J. 26, 2014-2020 (2017).

74. Bian, Q. et al. Mechanosignaling activation of TGF $\beta$ maintains intervertebral disc homeostasis. Bone Res. 5, 17008 (2017).

75. Zheng, L. et al. Ciliary parathyroid hormone signaling activates transforming growth factor-á to maintain intervertebral disc homeostasis during aging. Bone Res. 6, 21 (2018).

76. Oichi, T. et al. A mouse intervertebral disc degeneration model by surgically induced instability. Spine 43, E557-E564 (2018).

77. $\mathrm{Ni}$, S. et al. Sensory innervation in porous endplates by Netrin-1 from osteoclasts mediates PGE2-induced spinal hypersensitivity in mice. Nat. Commun. 10, 1-15 (2019).

78. Bradshaw, A. D. \& Sage, E. H. SPARC, a matricellular protein that functions in cellular differentiation and tissue response to injury. J. Clin. Investig. 107, 1049-1054 (2001).

79. Gruber, H. E., Ingram, J. A., Leslie, K. \& Hanley, E. N. Jr Cellular, but not matrix, immunolocalization of SPARC in the human intervertebral disc: decreasing localization with aging and disc degeneration. Spine 29, 2223-2228 (2004).

80. Gruber, H. E. et al. Targeted deletion of the SPARC gene accelerates disc degeneration in the aging mouse. J. Histochem. Cytochem. 53, 1131-1138 (2005).

81. James, G., Millecamps, M., Stone, L. S. \& Hodges, P. W. Dysregulation of the inflammatory mediators in the Multifidus muscle after spontaneous intervertebral disc degeneration SPARC-null mice is ameliorated by physical activity. Spine 43, E1184-E1194 (2018).

82. Millecamps, M., Tajerian, M., Sage, E. H. \& Stone, L. S. Behavioural signs of chronic back pain in the SPARC-null mouse. Spine 36, 95-102 (2011).

83. Millecamps, M., Tajerian, M., Naso, L., Sage, E. H. \& Stone, L. S. Lumbar intervertebral disc degeneration associated with axial and radiating low back pain in ageing SPARC-null mice. Pain 153, 1167-1179 (2012).

84. Millecamps, M., Czerminski, J. T., Mathieu, A. P. \& Stone, L. S. Behavioral signs of axial low back pain and motor impairment correlate with the severity of intervertebral disc degeneration in a mouse model. Spine J. 15, 2524-2537 (2015).

85. Krock, E. et al. Interleukin-8 as a therapeutic target for chronic low back pain: Upregulation in human cerebrospinal fluid and pre-clinical validation with chronic reparixin in the SPARC-null mouse model. EBioMedicine 43, 487-500 (2019).
86. Ding, $\mathrm{H}$. et al. Progranulin derived engineered protein Atsttrin suppresses TNFalpha-mediated inflammation in intervertebral disc degenerative disease. Oncotarget 8, 109692-109702 (2017).

87. Deng, X., Zhao, F., Kang, B. \& Zhang, X. Elevated interleukin-6 expression levels are associated with intervertebral disc degeneration. Exp. Ther. Med. 11, 1425-1432 (2016).

88. Suzuki, S. et al. Potential involvement of the IL-6/JAK/STAT3 pathway in the pathogenesis of intervertebral disc degeneration. Spine 42, E817-E824 (2017).

89. Gruber, H., Hoelscher, G., Ingram, J., Norton, H. \& Hanley, E. Jr Increased IL-17 expression in degenerated human discs and increased production in cultured annulus cells exposed to IL-1ß and TNF-a. Biotech. Histochem. 88, 302-310 (2013).

90. Fontana, G., See, E. \& Pandit, A. Current trends in biologics delivery to restore intervertebral disc anabolism. Adv. Drug Deliv. Rev. 84, 146-158 (2015).

91. Yang, H. et al. Secreted factors from intervertebral disc cells and infiltrating macrophages promote degenerated intervertebral disc catabolism. Spine $\mathbf{4 4}$, E520-E529 (2019).

92. Wang, J. et al. Tumor necrosis factor $\alpha$-and interleukin-1 $\beta$-dependent induction of CCL3 expression by nucleus pulposus cells promotes macrophage migration through CCR1. Arthritis Rheum. 65, 832-842 (2013).

93. Shen, C., Yan, J., Jiang, L.-S. \& Dai, L.-Y. Autophagy in rat annulus fibrosus cells: evidence and possible implications. Arthritis Res. Ther. 13, R132 (2011).

94. Purmessur, D. et al. A role for TNFa in intervertebral disc degeneration: a nonrecoverable catabolic shift. Biochem. Biophys. Res. Commun. 433, 151-156 (2013).

95. Zhang, J. et al. TNF-a enhances apoptosis by promoting chop expression in nucleus pulposus cells: role of the MAPK and NF-KB pathways. J. Orthop. Res. 37, 697-705 (2019).

96. Long, J. et al. JAG2/Notch2 inhibits intervertebral disc degeneration by modulating cell proliferation, apoptosis, and extracellular matrix. Arthritis Res. Ther. 21, 213 (2019)

97. Doita, M. et al. Influence of macrophage infiltration of herniated disc tissue on the production of matrix metalloproteinases leading to disc resorption. Spine 26, 1522-1527 (2001).

98. Jimbo, K., Park, J. S., Yokosuka, K., Sato, K. \& Nagata, K. Positive feedback loop of interleukin- $1 \beta$ upregulating production of inflammatory mediators in human intervertebral disc cells in vitro. J. Neurosurg. Spine 2, 589-595 (2005).

99. Le Maitre, C. L., Freemont, A. J. \& Hoyland, J. A. The role of interleukin-1 in the pathogenesis of human intervertebral disc degeneration. Arthritis Res. Ther. 7, R732 (2005).

100. Séguin, C. A., Pilliar, R. M., Roughley, P. J. \& Kandel, R. A. Tumor necrosis factora modulates matrix production and catabolism in nucleus pulposus tissue. Spine 30, 1940-1948 (2005).

101. Le Maitre, C. L., Hoyland, J. A. \& Freemont, A. J. Interleukin-1 receptor antagonist delivered directly and by gene therapy inhibits matrix degradation in the intact degenerate human intervertebral disc: an in situ zymographic and gene therapy study. Arthritis Res. Ther. 9, R83 (2007).

102. Bachmeier, B. E. et al. Matrix metalloproteinase expression levels suggest distinct enzyme roles during lumbar disc herniation and degeneration. Eur. Spine J. 18, 1573-1586 (2009).

103. Wang, J. et al. TNF- $\alpha$ and IL-1 $\beta$ promote a disintegrin-like and metalloprotease with thrombospondin type I motif-5-mediated aggrecan degradation through syndecan-4 in intervertebral disc. J. Biol. Chem. 286, 39738-39749 (2011).

104. Wang, $X$. et al. Tumor necrosis factor- $a$-and interleukin-1 $\beta$-dependent matrix metalloproteinase-3 expression in nucleus pulposus cells requires cooperative signaling via syndecan 4 and mitogen-activated protein kinase-NF- $\mathrm{KB}$ axis: implications in inflammatory disc disease. Am. J. Pathol. 184, 2560-2572 (2014).

105. Tian, Y. et al. Inflammatory cytokines associated with degenerative disc disease control aggrecanase-1 (ADAMTS-4) expression in nucleus pulposus cells through MAPK and NF-KB. Am. J. Pathol. 182, 2310-2321 (2013).

106. Ponnappan, R. K. et al. An organ culture system to model early degenerative changes of the intervertebral disc. Arthritis Res. Ther. 13, R171 (2011).

107. Gorth, D. J., Shapiro, I. M. \& Risbud, M. V. Transgenic mice overexpressing human TNF-a experience early onset spontaneous intervertebral disc herniation in the absence of overt degeneration. Cell Death Dis. 10, 7 (2018).

108. Gorth, D. J., Shapiro, I. M. \& Risbud, M. V. A new understanding of the role of IL-1 in age-related intervertebral disc degeneration in a Murine Model. J. Bone Miner. Res. 34, 1531-1542 (2019).

109. Gabr, M. A. et al. Interleukin-17 synergizes with IFNY or TNFa to promote inflammatory mediator release and intercellular adhesion molecule-1 (ICAM-1) expression in human intervertebral disc cells. J. Orthop. Res. 29, 1-7 (2011).

110. Studer, R. K., Vo, N., Sowa, G., Ondeck, C. \& Kang, J. Human nucleus pulposus cells react to IL-6: independent actions and amplification of response to IL-1 and TNF-a. Spine 36, 593-599 (2011). 
111. Bogduk, N., Tynan, W. \& Wilson, A. The nerve supply to the human lumbar intervertebral discs. J. Anat. 132(Pt 1), 39-56 (1981).

112. Grönblad, M., Weinstein, J. N. \& Santavirta, S. Immunohistochemical observations on spinal tissue innervation: a review of hypothetical mechanisms of back pain. Acta Orthop. Scand. 62, 614-622 (1991).

113. Fujii, K. et al. Discogenic back pain: literature review of definition, diagnosis, and treatment. JBMR Plus 3, e10180 (2019).

114. Burke, J. et al. Intervertebral discs which cause low back pain secrete high levels of proinflammatory mediators. J. Bone Jt. Surg. Br. 84, 196-201 (2002).

115. Andrade, P. et al. Elevated IL-1 $\beta$ and IL- 6 levels in lumbar herniated discs in patients with sciatic pain. Eur. Spine J. 22, 714-720 (2013).

116. Peng, B. et al. Possible pathogenesis of painful intervertebral disc degeneration. Spine 31, 560-566 (2006).

117. Richardson, S. M., Doyle, P., Minogue, B. M., Gnanalingham, K. \& Hoyland, J. A. Increased expression of matrix metalloproteinase-10, nerve growth factor and substance $P$ in the painful degenerate intervertebral disc. Arthritis Res. Ther. 11, R126 (2009).

118. Krock, E. et al. Painful, degenerating intervertebral discs up-regulate neurite sprouting and CGRP through nociceptive factors. J. Cell. Mol. Med. 18, 1213-1225 (2014)

119. Aoki, Y. et al. Disc inflammation potentially promotes axonal regeneration of dorsal root ganglion neurons innervating lumbar intervertebral disc in rats. Spine 29, 2621-2626 (2004).

120. Pezet, S. \& McMahon, S. B. Neurotrophins: mediators and modulators of pain. Annu. Rev. Neurosci. 29, 507-538 (2006).

121. Freemont, A. et al. Nerve growth factor expression and innervation of the painful intervertebral disc. J. Pathol. 197, 286-292 (2002).

122. Safieh-Garabedian, B., Poole, S., Allchorne, A., Winter, J. \& Woolf, C. J. Contribution of interleukin-1 $\beta$ to the inflammation-induced increase in nerve growth factor levels and inflammatory hyperalgesia. Br. J. Pharmacol. 115, 1265-1275 (1995).

123. Abe, Y. et al. Proinflammatory cytokines stimulate the expression of nerve growth factor by human intervertebral disc cells. Spine 32, 635-642 (2007).

124. Purmessur, D., Freemont, A. J. \& Hoyland, J. A. Expression and regulation of neurotrophins in the nondegenerate and degenerate human intervertebral disc. Arthritis Res. Ther. 10, R99 (2008).

125. Lee, J. M. et al. Interleukin-1 $\beta$ induces angiogenesis and innervation in human intervertebral disc degeneration. J. Orthop. Res. 29, 265-269 (2011).

126. Gruber, H., Hoelscher, G., Bethea, S. \& Hanley, E. Jr. Interleukin 1-beta upregulates brain-derived neurotrophic factor, neurotrophin 3 and neuropilin 2 gene expression and NGF production in annulus cells. Biotech. Histochem. 87, 506-511 (2012)

127. Van Tulder, M. et al. Chapter 3 European guidelines for the management of acute nonspecific low back pain in primary care. Eur. Spine J. 15, s169-s191 (2006).

128. Wuertz, K., Vo, N., Kletsas, D. \& Boos, N. Inflammatory and catabolic signalling in intervertebral discs: the roles of NF-KB and MAP kinases. Eur. Cell Mater. 23, 103-119 (2012)

129. Jiao, Y. et al. Propionibacterium acnes induces discogenic low back pain via stimulating nucleus pulposus cells to secrete pro-algesic factor of IL-8/CINC-1 through TLR2-NF-KB p65 pathway. J. Mol. Med. 97, 25-35 (2019).

130. Ahmed, A. S. et al. NF-KB-associated pain-related neuropeptide expression in patients with degenerative disc disease. Int. J. Mol. Sci. 20, 658 (2019).

131. Zhang, J. et al. TGF- $\beta 1$ suppresses CCL3/4 expression through the ERK signaling pathway and inhibits intervertebral disc degeneration and inflammation-related pain in a rat model. Exp. Mol. Med. 49, e379 (2017)

132. Krock, E. et al. Nerve growth factor is regulated by toll-like receptor 2 in human intervertebral discs. J. Biol. Chem. 291, 3541-3551 (2016).

133. Johnson, Z. I., Schoepflin, Z. R., Choi, H., Shapiro, I. M. \& Risbud, M. V. Disc in flames: Roles of TNF- $\alpha$ and IL-1 $\beta$ in intervertebral disc degeneration. Eur. Cells Mater. 30, 104-116 (2015).

134. Walter, B. A. et al. Reduced tissue osmolarity increases TRPV4 expression and pro-inflammatory cytokines in intervertebral disc cells. Eur. Cell Mater. 32 123-136 (2016)

135. Wagner, E. F. \& Nebreda, Á. R. Signal integration by JNK and p38 MAPK pathways in cancer development. Nat. Rev. Cancer 9, 537-549 (2009).

136. Huang, P., Han, J. \& Hui, L. MAPK signaling in inflammation-associated cancer development. Protein Cell 1, 218-226 (2010).

137. Kim, J.-H., Studer, R., Vo, N., Sowa, G. \& Kang, J. p38 MAPK inhibition selectively mitigates inflammatory mediators and VEGF production in AF cells co-cultured with activated macrophage-like THP-1 cells. Osteoarthr. Cartil. 17, 1662-1669 (2009).

138. Takeda, K. \& Akira, S. Toll-like receptors in innate immunity. Int. Immunol. 17, 1-14 (2005).

139. Klawitter, M. et al. Expression and regulation of toll-like receptors (TLRs) in human intervertebral disc cells. Eur. Spine J. 23, 1878-1891 (2014).
140. Li, Z. et al. Resistin promotes CCL4 expression through toll-like receptor- 4 and activation of the p38-MAPK and NF-KB signaling pathways: implications for intervertebral disc degeneration. Osteoarthr. Cartil. 25, 341-350 (2017).

141. Gawri, R. et al. High mechanical strain of primary intervertebral disc cells promotes secretion of inflammatory factors associated with disc degeneration and pain. Arthritis Res. Ther. 16, R21 (2014).

142. Navone, S. et al. Mechanical loading of intervertebral disc modulates microglia proliferation, activation, and chemotaxis. Osteoarthr. Cartil. 26, 978-987 (2018).

143. Tang, W. et al. The growth factor progranulin binds to TNF receptors and is therapeutic against inflammatory arthritis in mice. Science 332, 478-484 (2011).

144. Phillips, K. L., Jordan-Mahy, N., Nicklin, M. J. \& Le, C. L. Maitre, Interleukin-1 receptor antagonist deficient mice provide insights into pathogenesis of human intervertebral disc degeneration. Ann. Rheum. Dis. 72, 1860-1867 (2013).

145. Mak, T. W. \& Saunders, M. E. 17 - Cytokines and cytokine receptors. The Immune Response. (Academic Press: Burlington, 2006) 463-516.

146. Hao, S., Mata, M., Glorioso, J. C. \& Fink, D. J. HSV-mediated expression of interleukin-4 in dorsal root ganglion neurons reduces neuropathic pain. Mol. Pain. 2, 6 (2006).

147. Kedong, H., Wang, D., Sagaram, M., An, H. S. \& Chee, A. Anti-inflammatory effects of interleukin-4 on intervertebral disc cells. Spine J. 20, 60-68 (2020).

148. Yang, $\mathrm{H}$. et al. TGF-beta1 antagonizes TNF-alpha induced up-regulation of matrix metalloproteinase 3 in nucleus pulposus cells: role of the ERK1/2 pathway. Connect. Tissue Res. 56, 461-468 (2015).

149. Echeverry, S. et al. Transforming growth factor-beta1 impairs neuropathic pain through pleiotropic effects. Mol. Pain. 5, 16 (2009).

150. Williams, F. M. et al. GDF5 single-nucleotide polymorphism rs143383 is associated with lumbar disc degeneration in Northern European women. Arthritis Rheum. 63, 708-712 (2011).

151. Li, X., Leo, B. M., Beck, G., Balian, G. \& Anderson, G. D. Collagen and proteoglycan abnormalities in the GDF-5-deficient mice and molecular changes when treating disk cells with recombinant growth factor. Spine 29, 2229-2234 (2004).

152. Shen, L., Wu, Y., Han, L. \& Zhang, H. Overexpression of growth and differentiation factor- 5 inhibits inflammatory factors released by intervertebral disc cells. Exp. Ther. Med. 15, 3603-3608 (2018).

153. Wei, A. et al. Expression of growth differentiation factor 6 in the human developing fetal spine retreats from vertebral ossifying regions and is restricted to cartilaginous tissues. J. Orthop. Res. 34, 279-289 (2016).

154. Wei, A. et al. BMP13 prevents the effects of annular injury in an ovine model. Int. J. Biol. Sci. 5, 388-396 (2009).

155. Clarke, L. E. et al. Growth differentiation factor 6 and transforming growth factor-beta differentially mediate mesenchymal stem cell differentiation, composition, and micromechanical properties of nucleus pulposus constructs. Arthritis Res. Ther. 16, R67 (2014)

156. Gulati, T., Chung, S. A., Wei, A. Q. \& Diwan, A. D. Localization of bone morphogenetic protein 13 in human intervertebral disc and its molecular and functional effects in vitro in 3D culture. J. Orthop. Res. 33, 1769-1775 (2015).

157. Miyazaki, S. et al. ISSLS PRIZE IN BASIC SCIENCE 2018: Growth differentiation factor- 6 attenuated pro-inflammatory molecular changes in the rabbit anularpuncture model and degenerated disc-induced pain generation in the rat xenograft radiculopathy model. Eur. Spine J. 27, 739-751 (2018).

158. Cui, H. et al. Growth differentiation factor- 6 attenuates inflammatory and pain related factors and degenerated disc-induced pain behaviors in rat model. J. Orthop. Res. Online ahead of print. https://doi.org/10.1002/jor.24793 (2020).

159. Yoon, S. T. et al. ISSLS prize winner: LMP-1 upregulates intervertebral disc cell production of proteoglycans and BMPs in vitro and in vivo. Spine 29, 2603-2611 (2004).

160. Liu, H. et al. LIM mineralization protein-1 suppresses TNF-alpha induced intervertebral disc degeneration by maintaining nucleus pulposus extracellular matrix production and inhibiting matrix metalloproteinases expression. J. Orthop. Res. 33, 294-303 (2015).

161. Ye, F. et al. Role of SHOX2 in the development of intervertebral disc degeneration. J. Orthop. Res. 35, 1047-1057 (2017).

162. Chen, Y. et al. Melatonin ameliorates intervertebral disc degeneration via the potential mechanisms of mitophagy induction and apoptosis inhibition. J. Cell. Mol. Med. 23, 2136-2148 (2019).

163. Chen, F. et al. Melatonin alleviates intervertebral disc degeneration by disrupting the IL-1 $\beta /$ NF-KB-NLRP3 inflammasome positive feedback loop. Bone Res 8, 10 (2020).

164. Lai, A. et al. Dietary polyphenols as a safe and novel intervention for modulating pain associated with intervertebral disc degeneration in an in-vivo rat model. PloS ONE 14, e0223435 (2019).

165. Li, X. et al. Resveratrol attenuates inflammation environment-induced nucleus pulposus cell senescence in vitro. Biosci. Rep. 39, BSR20190126 (2019). 
166. Gao, J., Zhang, Q. \& Song, L. Resveratrol enhances matrix biosynthesis of nucleus pulposus cells through activating autophagy via the PI3K/Akt pathway under oxidative damage. Biosci. Rep. 38, BSR20180544 (2018).

167. Jiang, Y., Xie, Z., Yu, J. \& Fu, L. Resveratrol inhibits IL-1beta-mediated nucleus pulposus cell apoptosis through regulating the PI3K/Akt pathway. Biosci. Rep. 39, BSR20190043 (2019).

168. Wang, X. H. et al. Resveratrol attenuated TNF-alpha-induced MMP-3 expression in human nucleus pulposus cells by activating autophagy via AMPK/ SIRT1 signaling pathway. Exp. Biol. Med. 241, 848-853 (2016).

169. Wuertz, K. et al. The red wine polyphenol resveratrol shows promising potential for the treatment of nucleus pulposus-mediated pain in vitro and in vivo. Spine 36, E1373-E1384 (2011).

170. Klawitter, M. et al. Triptolide exhibits anti-inflammatory, anti-catabolic as well as anabolic effects and suppresses TLR expression and MAPK activity in IL-1 $\beta$ treated human intervertebral disc cells. Eur. Spine J. 21, 850-859 (2012).

171. Zhu, J. et al. Kaempferol slows intervertebral disc degeneration by modifying LPS-induced osteogenesis/adipogenesis imbalance and inflammation response in BMSCs. Int. Immunopharmacol. 43, 236-242 (2017).

172. Li, K., Li, Y., Xu, B., Mao, L. \& Zhao, J. Sesamin inhibits lipopolysaccharide-induced inflammation and extracellular matrix catabolism in rat intervertebral disc. Connect. Tissue Res. 57, 347-359 (2016).

173. Kim, J. S. et al. Lactoferricin mediates anti-inflammatory and anti-catabolic effects via inhibition of IL-1 and LPS activity in the intervertebral disc. J. Cell. Physiol. 228, 1884-1896 (2013).

174. Wang, X. et al. Potential therapeutic role of Co-Q10 in alleviating intervertebral disc degeneration and suppressing IL-1 beta-mediated inflammatory reaction in NP cells. Int. Immunopharmacol. 64, 424-431 (2018).

175. Ishimoto, $\mathrm{H}$. et al. In vivo anti-inflammatory and antioxidant properties of ellagitannin metabolite urolithin A. Bioorg. Med. Chem. Lett. 21, 5901-5904 (2011).

176. Ryu, D. et al. Urolithin A induces mitophagy and prolongs lifespan in C. elegans and increases muscle function in rodents. Nat. Med. 22, 879-888 (2016).

177. Liu, H. et al. A inhibits the catabolic effect of TNFalpha on nucleus pulposus cell and alleviates intervertebral disc degeneration in vivo. Front. Pharmacol. 9, 1043 (2018).

178. Karppinen, J. et al. Tumor necrosis factor-alpha monoclonal antibody, infliximab, used to manage severe sciatica. Spine 28, 750-753 (2003).

179. Cohen, S. P. et al. Randomized, double-blind, placebo-controlled, dose-response, and preclinical safety study of transforaminal epidural etanercept for the treatment of sciatica. Anesthesiology 110, 1116-1126 (2009).

180. ClinicalTrials.gov. Infliximab in chronic low back pain and modic changes. https://clinicaltrials.gov/ct2/show/NCT03704363?term=infliximab\&cond=low + back + pain\&draw $=2 \&$ rank $=1$ (2018).

181. Tsai, W. C. et al. Platelet-rich plasma releasate promotes regeneration and decreases inflammation and apoptosis of injured skeletal muscle. Am. J. Sports Med. 46, 1980-1986 (2018).

182. Andia, I. \& Maffulli, N. Platelet-rich plasma for managing pain and inflammation in osteoarthritis. Nat. Rev. Rheumatol. 9, 721-730 (2013).

183. Akeda K. et al. Intradiscal injection of autologous serum isolated from plateletrich-plasma for the treatment of discogenic low back pain: preliminary prospective clinical trial. General posters GP141, p. Poster No. 2194 (ISSLS meeting, Gothenburg, Sweden, 2011).
184. Akeda, K. et al. Intradiscal injection of autologous platelet-rich plasma releasate to treat discogenic low back pain: a preliminary clinical trial. Asian Spine J. 11, 380-389 (2017).

185. Levi, D. et al. Intradiscal platelet-rich plasma injection for chronic discogenic low back pain: preliminary results from a prospective trial. Pain. Med. 17, 1010-1022 (2016).

186. Tuakli-Wosornu, Y. A. et al. Lumbar intradiskal platelet-rich plasma (PRP) injections: a prospective, double-blind, randomized controlled study. PM R. 8, 1-10 (2016).

187. Lutz, G. E. Increased nuclear T2 signal intensity and improved function and pain in a patient one year after an intradiscal platelet-rich plasma injection. Pain. Med. 18, 1197-1199 (2017).

188. Mantyh, P. W., Koltzenburg, M., Mendell, L. M., Tive, L. \& Shelton, D. L. Antagonism of nerve growth factor-TrkA signaling and the relief of pain. Anesthesiology 115, 189-204 (2011).

189. Katz, N. et al. Efficacy and safety of tanezumab in the treatment of chronic low back pain. Pain 152, 2248-2258 (2011).

190. Kivitz, A. J. et al. Efficacy and safety of tanezumab versus naproxen in the treatment of chronic low back pain. Pain 154, 1009-1021 (2013).

191. Gimbel, J. S. et al. Long-term safety and effectiveness of tanezumab as treatment for chronic low back pain. Pain 155, 1793-1801 (2014).

192. Hochberg, M. C. et al. When is osteonecrosis not osteonecrosis?: adjudication of reported serious adverse joint events in the tanezumab clinical development program. Arthritis Rheumatol. 68, 382-391 (2016).

193. Ho, G., Leung, V. Y., Cheung, K. M. \& Chan, D. Effect of severity of intervertebral disc injury on mesenchymal stem cell-based regeneration. Connect. Tissue Res. 49, 15-21 (2008)

194. Lotz, J., Fields, A. \& Liebenberg, E. The role of the vertebral end plate in low back pain. Glob. Spine J. 3, 153-164 (2013).

195. Lv, B. et al. Relationship between endplate defects, modic change, disc degeneration, and facet joint degeneration in patients with low back pain. Biomed. Res. Int. 2019, 9369853 (2019).

196. Bailey, J. F. et al. The relationship between endplate pathology and patientreported symptoms for chronic low back pain depends on lumbar paraspinal muscle quality. Spine 44, 1010-1017 (2019).

197. Munir, S. et al. Endplate defect is heritable, associated with low back pain and triggers intervertebral disc degeneration: a longitudinal study from TwinsUK. Spine 43, 1496-1501 (2018).

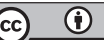

Open Access This article is licensed under a Creative Commons Attribution 4.0 International License, which permits use, sharing, adaptation, distribution and reproduction in any medium or format, as long as you give appropriate credit to the original author(s) and the source, provide a link to the Creative Commons license, and indicate if changes were made. The images or other third party material in this article are included in the article's Creative Commons license, unless indicated otherwise in a credit line to the material. If material is not included in the article's Creative Commons license and your intended use is not permitted by statutory regulation or exceeds the permitted use, you will need to obtain permission directly from the copyright holder. To view a copy of this license, visit http://creativecommons. org/licenses/by/4.0/.

(c) The Author(s) 2021 